\title{
Occupation and mesothelioma in Sweden: updated incidence in men and women in the 27 years after the asbestos ban
}

\author{
Nils Plato ${ }^{1}$, Jan Ivar Martinsen², Pär Sparén ${ }^{3}$, Gunnar Hillerdal ${ }^{4}$, Elisabete Weiderpass ${ }^{2,3,5,6}$ \\ ${ }^{1}$ Institute of Environmental Medicine, Karolinska Institutet, Stockholm, Sweden; '2Department of Research, Cancer Registry of Norway, Institute \\ of Population-Based Cancer Research, Oslo, Norway; ${ }^{3}$ Department of Medical Epidemiology and Biostatistics, Karolinska Institutet, Stockholm; \\ ${ }^{4}$ Department of Medicine, Karolinska Institutet, Stockholm, Sweden; ${ }^{5}$ Department of Community Medicine, Faculty of Health Science, University \\ of Tromsø, The Arctic University of Norway, Tromsø, Norway; ${ }^{6}$ Genetic Epidemiology Group, Folkhälsan Research Center, Helsinki, Finland
}

OBJECTIVES: We updated the Swedish component of the Nordic Occupational Cancer (NOCCA) Study through 2009 in order to investigate the incidence of mesothelioma of the peritoneum and pleura in both genders, and explored occupational exposures that may be associated with mesothelioma.

METHODS: The Swedish component of the NOCCA Study includes 6.78 million individuals. Data from this cohort were linked to the population-based Swedish Cancer Registry and Swedish Total Population Registry for three periods between 1961 and 2009, and then further linked to the Swedish NOCCA job-exposure matrix, which includes 25 carcinogenic substances and the corresponding exposure levels for 280 occupations. Multivariate analysis was used to calculate standardized incidence ratios (SIRs) for mesothelioma of the peritoneum and pleura by gender, occupational category, carcinogenic substance, and for multiple occupational exposures simultaneously.

RESULTS: A total of 3,716 incident mesotheliomas were recorded (21.1\% in women). We found a significantly increased risk of mesothelioma in 24 occupations, as well as clear differences between the genders. Among men, increased risks of mesothelioma of the pleura were observed in male-dominated occupations, with the greatest elevation of risk among plumbers (SIR, 4.99; 95\% confidence interval, 4.20 to 5.90). Among women, increased risks were observed in sewing workers, canning workers, packers, cleaners, and postal workers. In multivariate analysis controlling for multiple occupational exposures, significant associations were only observed between asbestos exposure and mesothelioma.

CONCLUSIONS: Asbestos exposure was associated with mesothelioma incidence in our study. The asbestos ban of 1982 has yet to show any clear effect on the occurrence of mesothelioma in this cohort. Among women, the occupations of canning workers and cleaners showed increased risks of mesothelioma of the pleura without evidence of asbestos exposure.

KEY WORDS: Epidemiology, Asbestos, Job-exposure matrix, Carcinogenic substances

Correspondence: Elisabete Weiderpass

Department of Medical Epidemiology and Biostatistics, Karolinska Institutet, P.O. Box 281, Stockholm 171 77, Sweden

Tel: +46-852482365, Fax: +46-8311101

E-mail: elisabete.weiderpass.vainio@ki.se

Received: Jul 19, 2016, Accepted: Sep 20, 2016, Published: Sep 20, 2016 This article is available from: http://e-epih.org/

(C) 2016, Korean Society of Epidemiology

(C) This is an open-access article distributed under the terms of the Creative Commons Attribution License (http://creativecommons.org/licenses/by/4.0/), which permits unrestricted use, distribution, and reproduction in any medium, provided the original work is properly cited.

\section{INTRODUCTION}

Mesothelioma is a very aggressive malignancy that occurs in the peritoneum and pleura, and more rarely in the pericardium. It is most often linked to occupational asbestos exposure and was classified as an occupational disease in the 1950s [1]. Mesothelioma has a poor prognosis, with most patients dying within one year of diagnosis [2], and a long latency period of up to 40 years [3].The incidence of mesothelioma varies; its incidence in developed countries such as Belgium, Britain, and Australia exceeds 30 cases per one million inhabitants [4], and in Swe- 
den approximately 12 cases are diagnosed per one million inhabitants (approximately 120 cases per year) [5].

Mesothelioma development is most strongly associated with exposure to asbestos types from the amphibole family, of which crocidolite was the most prevalent type used in Sweden. Therefore, occupations in which crocidolite was used or manipulated constituted high-risk occupations. In some industries, such as asbestos-cement production, asbestos types from both the serpentine and amphibole families were used [6].

Asbestos was banned in Sweden in 1982 [7], and strict precautions and security requirements have been introduced for occupations that include the handling of or exposure to asbestos, such as asbestos removal. A sharp decline in the annual incidence rate of mesothelioma was observed in 2008 [8], but in the last two years its incidence has started to increase again. One of the reasons for this recent increase may be the long latency period of mesothelioma; however, since asbestos has been absent from the Swedish labor market for 35 years, one would expect the number of mesothelioma cases to be on the decline. Instead, at present more people in Sweden die from mesothelioma than from accidents in the workplace [9].

Only a limited number of occupations have been reported to confer a significant excess risk of mesothelioma [10], and no connection between mesothelioma and any occupational exposure besides asbestos, such as air pollution [11], has been scientifically proven. In the UK and Finland, it has been estimated that $97 \%$ [12] and 90\% [13] of mesothelioma cases, respectively, are related to asbestos exposure, and most of these are caused by occupational exposure.

The most recent report on the Nordic Occupational Cancer (NOCCA) cohort covered the period from 1961 to 2005 and is the largest study of occupational cancer in the Nordic countries published so far. It included 2.8 million diagnosed cases of cancer in the five Nordic countries (Denmark, Finland, Iceland, Norway, and Sweden) and reported mesothelioma cases in occupations where asbestos exposure is not usually considered to be present [14]. A total of $40.6 \%$ of the mesothelioma cases in the NOCCA cohort were from Sweden (2,521 men and 548 women), and a statistically significant excess risk of mesothelioma among men in Sweden was found in 12 of the 53 occupational categories considered [14]. However, the proportion of women diagnosed with mesothelioma was also quite high.

Asbestos exposure alone probably cannot explain the relatively high proportion of women with mesothelioma in Sweden, since disease onset was found to occur at approximately 50 years of age, which is much earlier than the onset for men [5]. Moreover, asbestos exposure during the period covered by the NOCCA Study was most common in male-dominated occupations (e.g., insulators, ship builders, car mechanics, asbestos cement manufacturing, construction workers, etc.) [15]. How- ever, since $17.8 \%$ of the mesothelioma cases in the latest Swedish NOCCA Study occurred in women [14], it is important to identify alternative direct or indirect causal factors.

Therefore, we updated the data in the Swedish component of the NOCCA Study through 2009 in order to investigate the incidence of mesothelioma of the peritoneum and pleura in both genders, and to explore occupational exposures other than asbestos that may be associated with mesothelioma. We also investigated whether mesothelioma incidence during the period from 1961 to 2009 differed among occupations and whether it was possible to see any effect of the Swedish asbestos ban of 1982.

\section{MATERIALS AND METHODS}

\section{The Swedish Nordic Occupational Cancer Study}

The NOCCA Study was started to investigate occupational exposures and their associations with cancer incidence. The Swedish component of the NOCCA Study consists of individuals who participated in one of the following Swedish population censuses: 1960,1970, 1980, or 1990. The 1960, 1970, and 1990 censuses took place on November 1, while the 1980 census took place on September 15. The Swedish NOCCA Study included 6.78 million individuals aged 30 to 64 years who were still alive and living in Sweden on January 1 of the year following the census. Each individual's personal identification number, name, address, marital status, education, economic activity, occupation, and industry were recorded, and the occupations were then coded, as described previously by Pukkala et al. [14], according to a Swedish adaptation of the Nordic Occupational Classification [16], which is a Nordic adaptation of the International Standard Classification of Occupations from 1958 [17].

\section{Update of cancer incidence through 2009}

Cancer incidence was determined through record linkage between the Swedish NOCCA database and the population-based Swedish Cancer Registry. The present report updated information on cancer incidence in subjects included in the Swedish NOCCA Study through 2009, thus covering the period from 1961 to 2009. Follow-up was done over three time periods: 1961-1974, 1975-1989, and 1990-2009. Mesothelioma cases were classified into mesothelioma of the peritoneum (International Classification of Diseases, 7th revision [ICD-7] code 158) and of the pleura (ICD-7 code 162.2). Histological results were coded with three digits by the Swedish Cancer Registry (code 776), according to the official codes of the World Health Organization [18].

Study entry was set at January 1 of the year after the first available census in which an individual participated. Person-years 
were accumulated until the date of emigration, death, or the end of the study period (December 31, 2009), whichever came first. Dates of death and emigration were retrieved from the Swedish Total Population Registry.

\section{Standardized incidence ratio}

The observed number of mesothelioma cases and person-years were stratified into 5 -year age categories $(30-34,35-39, \ldots, \geq 85$ years) and 5 -year calendar periods by gender and occupational category. Standardized incidence ratios (SIRs) were calculated using cancer incidence rates for the entire Swedish population by gender, age, and calendar time as reference rates. The exact 95\% confidence interval (CI) was defined assuming a Poisson distribution of the observed number of cases.

\section{The Nordic Occupational Cancer job-exposure matrix}

The NOCCA job-exposure matrix (NOCCA-JEM) contains combined information from all the Nordic countries. It includes 25 carcinogenic substances with exposure levels for 280 occupations based on exposure data from national exposure databases and expert assessments available from 1945 to 1994 [19]. The NOCCA-JEM is quantitative; therefore, in principle it is possible to estimate the cumulative exposure (dose) of the 25 included carcinogenic substances for the entire NOCCA cohort.

The Finnish JEM (FINJEM) [20] was created by the Finnish Institute of Occupational Health in Helsinki, Finland. This is a generic quantitative JEM from 1945 onwards for 84 different outcomes, with exposures for almost 300 different occupations at 3-digit levels. This JEM is now used in many different countries. The FINJEM was used to construct national NOCCA JEMs for Denmark, Finland, Iceland, Norway, and Sweden. The exposure codes, definitions, and units of the carcinogenic substances included in the Swedish NOCCA-JEM can be found in Appendix 1. The Swedish NOCCA-JEM uses the 3-digit occupation codes used in the Swedish adaptation of the Nordic Occupational Classification. The data of the Swedish NOCCA Study were linked to the Swedish NOCCA-JEM to determine the exposures that occurred in the different occupations. Exposure information that went beyond the confines of the NOCCA-JEMs was obtained by an experienced occupational hygienist. Of the 280 occupational codes in the Swedish NOCCA Study, 96 were rated for occupational exposure to carcinogenic substances in the Swedish NOCCA-JEM.

Finally, mesothelioma incidence was linked with the Swedish NOCCA-JEM [19] and the observed number of cases was recorded by gender and by exposure to the carcinogenic substances included in the Swedish NOCCA-JEM.

The Swedish NOCCA Study received ethics committee/institutional review board approval from the Forskningsetikkommitten at the Karolinska Institutet (Dnr 03-466).

\section{RESULTS}

A total of 3,716 cases of mesothelioma were diagnosed in the cohort of the Swedish NOCCA Study from 1961 to 2009, $785(21.1 \%)$ of which occurred in women. The vast majority of cases $(89.7 \%)$ had mesothelioma of the pleura, while a small proportion was diagnosed with mesothelioma of the peritoneum (10.3\%). However, only 577 of the 3,334 cases of mesothelioma of the pleura occurred in women (17.3\%), as opposed to 208 of the $382(54.5 \%)$ cases of mesothelioma of the peritoneum. We found a significant excess risk of incident mesothelioma of both the peritoneum and pleura in 24 of the 280 occupations considered. Differences in risk between the genders were also found. Five occupations showed an excess risk in women, but no excess risk in men (Tables 1 and 2).

For men, the linkage of cancer incidence with the Swedish NOCCA-JEM resulted in the identification of 17 occupations with chemical exposure that conferred a significant excess risk of mesothelioma of the pleura, four of which also showed an excess risk of mesothelioma of the peritoneum: plumbers and pipe fitters (pleura: SIR, 4.99; 95\% CI, 4.20 to 5.90; peritoneum: SIR, 3.56; 95\% CI, 1.31 to 7.76), painters (pleura: SIR, 1.72; $95 \%$ CI, 1.35 to 2.16; peritoneum: SIR, 2.70; $95 \%$ CI, 1.08 to 5.56 ), bricklayers (pleura: SIR, $1.60 ; 95 \%$ CI, 1.07 to 2.30; peritoneum: SIR, 5.42 ; $95 \% \mathrm{CI}, 1.99$ to 11.80 ), and insulators (pleura: SIR, 10.9; 95\% CI, 6.81 to 16.50; peritoneum: SIR, 64.70; 95\% CI, 28.00 to 128.00) (Table 1, Appendix 2). Twelve of the 17 occupations with excess risk are rated for asbestos exposure in the Swedish NOCCA-JEM. However, most of these occupations are also rated for other exposures in the Swedish NOCCA-JEM. Moreover, the Swedish NOCCA-JEM indicates that the observed excess risk for mesothelioma of the pleura among mechanical engineers and technicians (SIR, 1.67; $95 \%$ CI, 1.42 to 1.95$)$; toolmakers, machine-tool setters, and operators (SIR, 1.48; 95\% CI, 1.22 to 1.77); chemical process workers (SIR, 2.15; 95\% CI, 1.20 to 3.54); paper pulp workers (SIR, 2.10; 95\% CI, 1.22 to 3.36); and stationary engine and related equipment operators (SIR, 1.77; 95\% CI, 1.05 to 2.79 ) is not sufficiently high to classify them as occupations that include asbestos exposure (Table 1). An elevated risk of mesothelioma of the pleura was also observed in two occupations that are not rated for chemical exposure in the Swedish NOCCA-JEM: ships' engineers (SIR, 6.06; 95\% CI, 3.65 to 9.46), and divers and pipe layers (SIR, 4.20; 95\% CI, 1.14 to 10.7) (Table 1, Appendix 3). The highest risk of mesothelioma of the pleura was observed for insulators ( $\mathrm{SIR}=10.9$ ), and the largest number of cases was observed among machinery fitters and machinery assemblers $(\mathrm{n}=180)$.

When women with mesothelioma were linked to the Swedish NOCCA-JEM, we observed an excess risk of mesothelioma of the pleura for one occupation rated for chemical exposure: 
Table 1. Observed number of mesotheliomas in the peritoneum and pleura among men in Sweden and SIRs from 1961 to 2009

\begin{tabular}{|c|c|c|c|c|c|c|c|c|}
\hline \multirow{2}{*}{ NYK } & \multirow{2}{*}{ Occupational title, 1980} & \multirow{2}{*}{$\mathrm{N}$} & \multicolumn{3}{|c|}{ Peritoneum (ICD-7 158) } & \multicolumn{3}{|c|}{ Pleura (ICD-7 162.2) } \\
\hline & & & Obs & SIR & $95 \% \mathrm{Cl}$ & Obs & SIR & $95 \% \mathrm{Cl}$ \\
\hline \multicolumn{9}{|c|}{ Occupations exposed to carcinogenic substances } \\
\hline 003 & Mechanical engineers and technicians & 102,447 & 6 & 1.08 & $0.40,2.36$ & 158 & 1.67 & $1.42,1.95$ \\
\hline 631 & Railway engine drivers and assistants & 9,605 & 1 & 1.71 & $0.04,9.54$ & 19 & 1.82 & $1.09,2.84$ \\
\hline 750 & Toolmakers, machine-tool setters, and operators & 95,837 & 7 & 1.43 & $0.57,2.94$ & 120 & 1.48 & $1.22,1.77$ \\
\hline 751 & Machinery fitters and machine assemblers & 127,226 & 6 & 0.96 & $0.35,2.10$ & 180 & 1.75 & $1.50,2.02$ \\
\hline 753 & Sheet metal workers & 38,172 & 3 & 1.55 & $0.32,4.52$ & 140 & 4.38 & $3.68,5.17$ \\
\hline 754 & Plumbers and pipe fitters & 31,515 & 6 & 3.56 & $1.31,7.76$ & 139 & 4.99 & $4.20,5.90$ \\
\hline 755 & Welders and flame cutters & 41,203 & 3 & 1.45 & $0.30,4.24$ & 54 & 1.57 & $1.18,2.04$ \\
\hline 761 & Electrical fitters and wiremen & 63,493 & 7 & 2.21 & $0.89,4.55$ & 119 & 2.28 & $1.89,2.72$ \\
\hline 771 & Construction carpenters and joiners & 83,073 & 2 & 0.46 & $0.06,1.67$ & 98 & 1.40 & $1.14,1.70$ \\
\hline 781 & Painters & 49,244 & 7 & 2.70 & $1.08,5.56$ & 73 & 1.72 & $1.35,2.16$ \\
\hline 791 & Bricklayers & 18,956 & 6 & 5.42 & $1.99,11.80$ & 29 & 1.60 & $1.07,2.30$ \\
\hline 794 & Insulators & 2,589 & 8 & 64.70 & $28.0,128.00$ & 22 & 10.90 & $6.81,16.50$ \\
\hline 799 & Non-specified other building and construction work & 7,333 & 0 & 0.00 & $0.00,7.42$ & 22 & 2.75 & $1.72,4.17$ \\
\hline 831 & Chemical process workers & 8,783 & 0 & 0.00 & $0.00,8.44$ & 15 & 2.15 & $1.20,3.54$ \\
\hline 834 & Paper pulp workers & 9,431 & 0 & 0.00 & $0.00,7.29$ & 17 & 2.10 & $1.22,3.36$ \\
\hline 871 & Stationary engine and related equipment operators & 11,851 & 2 & 3.14 & $0.38,11.30$ & 18 & 1.77 & $1.05,2.79$ \\
\hline 873 & Riggers and cable splicers & 269 & 0 & 0.00 & $0.00,252.00$ & 2 & 8.64 & $1.05,31.20$ \\
\hline \multicolumn{9}{|c|}{ Occupations unexposed to carcinogenic substances agents } \\
\hline 603 & Ships' engineers & 3,895 & 1 & 5.32 & $0.13,29.60$ & 19 & 6.06 & $3.65,9.46$ \\
\hline 797 & Divers and pipe layers & 2,983 & 0 & 0.00 & $0.00,56.90$ & 4 & 4.20 & $1.14,10.70$ \\
\hline
\end{tabular}

SIR, standardized incidence ratio; NYK, Nordic Occupational Classification; N, number of persons in follow-up; ICD, International Classification of Diseases; Obs, observed; $\mathrm{Cl}$, confidence interval.

Table 2. Observed number of mesotheliomas in the peritoneum and pleura among women in Sweden and SIRs from 1961 to 2009

\begin{tabular}{|c|c|c|c|c|c|c|c|c|}
\hline \multirow{2}{*}{ NYK } & \multirow{2}{*}{ Occupational title, 1980} & \multirow{2}{*}{$\mathrm{N}$} & \multicolumn{3}{|c|}{ Peritoneum (ICD-7 158) } & \multicolumn{3}{|c|}{ Pleura (ICD-7 162.2) } \\
\hline & & & Obs & SIR & $95 \% \mathrm{Cl}$ & Obs & SIR & $95 \% \mathrm{Cl}$ \\
\hline \multicolumn{9}{|c|}{ Occupations exposed to carcinogenic substances } \\
\hline 718 & Sewing work n.e.c. & 33,031 & 2 & 0.75 & $0.09,2.70$ & 18 & 2.14 & $1.27,3.39$ \\
\hline \multicolumn{9}{|c|}{ Occupations unexposed to carcinogenic substances } \\
\hline 661 & Sorting clerks and postal workers & 6,028 & 2 & 9.27 & $1.12,33.50$ & 1 & 1.47 & $0.04,8.21$ \\
\hline 825 & Canning workers & 3,882 & 0 & 0.00 & $0.00,13.40$ & 4 & 4.90 & $1.33,12.50$ \\
\hline 881 & Packers & 15,318 & 4 & 4.49 & $1.22,11.50$ & 3 & 1.07 & $0.22,3.13$ \\
\hline 932 & Cleaners & 103,538 & 7 & 1.21 & $0.49,2.49$ & 27 & 1.59 & $1.05,2.31$ \\
\hline
\end{tabular}

SIR, standardized incidence ratio; NYK, Nordic Occupational Classification; N, number of persons in follow-up; ICD, International Classification of Diseases; Obs, observed; Cl, confidence interval; n.e.c., not elsewhere classified.

sewing work (SIR, 2.14; 95\% CI, 1.27 to 3.39) (Table 2, Appendix 4). We observed significant excess risks of mesothelioma of the pleura in two occupations not rated for chemical exposure in the Swedish NOCCA-JEM: canning workers (SIR, 4.90; 95\% CI, 1.33 to 12.50 ) and cleaners (SIR, 1.59; 95\% CI, 1.05 to 2.31). In total, 208 women had mesothelioma of the peritoneum, of whom 104 were economically inactive. The other 104 women were distributed among 280 occupations, of which only two had a significant excess risk: sorting clerks and postal workers (SIR, 9.27; 95\% CI, 1.12 to 33.50 ) and packers (SIR, 4.49; 95\% CI, 1.22 to 11.50) (Table 2,Appendix 5).

We examined the trends over the three follow-up periods:
1961-1974, 1975-1989, and 1990-2009. The significant excess risk of mesothelioma of the peritoneum was constant over time for plumbers and pipefitters as well as for electrical fitters and wiremen. For sheet metal workers and electrical fitters and wiremen, we observed an increased risk during all three follow-up periods, while we observed a decreased risk for stationary engine and related equipment operators, mechanical engineers and technicians, machinery fitters and machinery assemblers, welding and flame cutters, and ships' engineers among men, and sewing work among women (Table 3). For mesothelioma of the peritoneum, we observed a decreased risk for insulators but no consistent trends for any other occupation (Table 4). 
Table 3. Observed number of mesotheliomas of the pleura among men and women in Sweden and SIRs for three time periods; 1961-1974, 1975-1989, and 1990-2009

\begin{tabular}{|c|c|c|c|c|c|c|c|c|c|c|}
\hline \multirow{2}{*}{ NYK } & \multirow{2}{*}{ Occupational title } & \multicolumn{3}{|c|}{$1961-1974$} & \multicolumn{3}{|c|}{ 1975-1989 } & \multicolumn{3}{|c|}{ 1990-2009 } \\
\hline & & Obs & SIR & $95 \% \mathrm{Cl}$ & Obs & SIR & $95 \% \mathrm{Cl}$ & Obs & SIR & $95 \% \mathrm{Cl}$ \\
\hline \multicolumn{11}{|c|}{ Exposed to chemical agents, men } \\
\hline 003 & Mechanical engineers and technicians & 4 & 1.31 & $0.36,3.37$ & 42 & 1.85 & $1.34,2.51$ & 112 & 1.62 & $1.34,1.95$ \\
\hline 750 & Toolmakers, machine-tool setters and operators & 4 & 1.16 & $0.32,2.97$ & 40 & 1.83 & $1.31,2.49$ & 76 & 1.36 & $1.07,1.70$ \\
\hline 751 & Machinery fitters and machine assemblers & 10 & 2.67 & $1.28,4.91$ & 52 & 2.03 & $1.51,2.66$ & 118 & 1.60 & $1.33,1.92$ \\
\hline 753 & Sheet metal workers & 4 & 2.75 & $0.75,7.04$ & 38 & 4.27 & $3.02,5.86$ & 98 & 4.53 & $3.68,5.52$ \\
\hline 754 & Plumbers and pipe fitters & 5 & 4.12 & $1.34,9.62$ & 44 & 5.80 & $4.22,7.79$ & 90 & 4.73 & $3.80,5.81$ \\
\hline 755 & Welders and flame cutters & 4 & 3.90 & $1.06,9.98$ & 15 & 1.83 & $1.02,3.01$ & 35 & 1.39 & $0.97,1.93$ \\
\hline 761 & Electrical fitters and wiremen & 4 & 2.09 & $0.57,5.35$ & 27 & 2.13 & $1.40,3.10$ & 88 & 2.34 & $1.87,2.88$ \\
\hline 771 & Construction carpenters and joiners & 3 & 0.66 & $0.14,1.92$ & 34 & 1.45 & $1.01,2.03$ & 61 & 1.45 & $1.11,1.86$ \\
\hline 781 & Painters & 4 & 1.57 & $0.43,4.01$ & 20 & 1.46 & $0.89,2.25$ & 49 & 1.88 & $1.39,2.48$ \\
\hline 794 & Insulators & 0 & 0.00 & $0.00,42.10$ & 7 & 12.81 & $5.15,26.40$ & 15 & 10.79 & $6.04,17.80$ \\
\hline 799 & Non-specified other building and construction work & 0 & 0.00 & $0.00,7.91$ & 7 & 2.70 & $1.09,5.57$ & 15 & 3.04 & $1.70,5.01$ \\
\hline 831 & Chemical process workers & 2 & 3.70 & $0.45,13.40$ & 3 & 1.18 & $0.24,3.46$ & 10 & 2.55 & $1.22,4.69$ \\
\hline 871 & Stationary engine and related equipment operators & 5 & 5.87 & $1.91,13.70$ & 5 & 1.32 & $0.43,3.08$ & 8 & 1.44 & $0.62,2.84$ \\
\hline 873 & Riggers and cable splicers & 0 & 0.00 & $0.00,178.00$ & 0 & 0.00 & $0.00,41.8$ & 2 & 16.33 & $1.98,59.00$ \\
\hline \multicolumn{11}{|c|}{ Unexposed to chemical agents, men } \\
\hline 603 & Ships' engineers & 0 & 0.00 & $0.00,23.60$ & 7 & 7.88 & $3.17,16.20$ & 12 & 5.73 & $2.96,10.00$ \\
\hline 797 & Divers and pipelayers & & & & 0 & 0.00 & $0.00,42.50$ & 4 & 4.62 & $1.26,11.80$ \\
\hline \multicolumn{11}{|c|}{ Exposed to chemical agents, women } \\
\hline 718 & Sewing work n.e.c. & 4 & 5.65 & $1.54,14.50$ & 9 & 3.07 & $1.40,5.83$ & 5 & 1.05 & $0.34,2.45$ \\
\hline
\end{tabular}

SIR, standardized incidence ratio; NYK, Nordic Occupational Classification; Obs, observed; Cl, confidence interval; n.e.c., not elsewhere classified.

Table 4. Observed number of mesotheliomas of the peritoneum among men and women in Sweden and SIRs for three time periods; 19611974, 1975-1989, and 1990-2009

\begin{tabular}{|c|c|c|c|c|c|c|c|c|c|c|}
\hline \multirow{2}{*}{ NYK } & \multirow{2}{*}{ Occupational title } & \multicolumn{3}{|c|}{$1961-1974$} & \multicolumn{3}{|c|}{$1975-1989$} & \multicolumn{3}{|c|}{ 1990-2009 } \\
\hline & & Obs & SIR & $95 \% \mathrm{Cl}$ & Obs & SIR & $95 \% \mathrm{Cl}$ & Obs & SIR & $95 \% \mathrm{Cl}$ \\
\hline \multicolumn{11}{|c|}{ Exposed to chemical agents, men } \\
\hline 754 & Plumbers and pipe fitters & 0 & 0.00 & $0.00,30.60$ & 2 & 3.11 & $0.38,11.3$ & 4 & 4.34 & $1.18,11.10$ \\
\hline 761 & Electrical fitters and wiremen & 0 & 0.00 & $0.00,19.70$ & 1 & 0.93 & $0.02,5.18$ & 6 & 3.14 & $1.15,6.85$ \\
\hline 791 & Bricklayers & 1 & 7.89 & $0.20,43.90$ & 3 & 5.85 & $1.21,17.10$ & 2 & 4.28 & $0.52,15.50$ \\
\hline 794 & Insulators & 3 & 346.21 & $71.40,1,012.00$ & 3 & 65.27 & $13.50,191.00$ & 2 & 29.01 & $3.51,105.00$ \\
\hline \multicolumn{11}{|c|}{ Unexposed to chemical agents, women } \\
\hline 661 & Sorting clerks and postal workers & 0 & 0.00 & $0.00,454.00$ & 0 & 0.00 & $0.00,85.20$ & 2 & 12.16 & $1.47,43.90$ \\
\hline
\end{tabular}

SIR, standardized incidence ratio; NYK, Nordic Occupational Classification; Obs, observed; Cl, confidence interval; n.e.c., not elsewhere classified.

\section{DISCUSSION}

Mesothelioma is closely related to asbestos exposure [1,21]. Despite the ban on asbestos put in place in Sweden in 1982 [7], the incidence rate of mesothelioma increased in subsequent decades, flattened out in 2000, and started to decrease after 2005 [8]. A total of 3,716 individuals in the Swedish NOCCA Study were diagnosed with mesothelioma from 1961 to 2009. The predominant type of mesothelioma in both genders was mesothelioma of the pleura, which was also much more common in men than in women. The proportion of women with mesothelioma of the pleura was $17.8 \%$, but when mesothelioma of the peritoneum was included, the proportion of women with mesothelioma increased to $21.1 \%$. Only $0.7 \%$ of all cases of mesothelioma are pericardial mesothelioma [22].

Men in traditionally male-dominated occupations, such as sheet metal workers, plumbers, welders, and others, had a significantly increased risk, while we did not observe any cases of mesothelioma among women in those occupations. This is probably due to the fact that there are few women in these occupations, and that job activities and exposure patterns can differ between genders. In occupations dominated by women, significantly increased risks were found among packers, sewing workers, cleaners, canning workers, and sorting clerks and postal workers. Sew- 
ing work showed the highest increased risk of mesothelioma of the pleura in the first period (1961-1974) (SIR, 5.65; 95\% CI, 1.54 to 14.50), the second period (1975-1989) (SIR, 3.07; 95\% CI, 1.40 to 5.83), and the full period (1961-2009) (SIR, 2.14; $95 \% \mathrm{CI}, 1.27$ to 3.39 ). Sewing workers are exposed to fibers, but not to asbestos fibers. However, exposure to asbestos fibers in the textile industry did occur in two small workshops in Sweden after the Second World War (Professor S. Krantz, personal communication). It may be that the asbestos-containing brake shoes in the textile machines caused a background level of airborne asbestos fibers in the machine halls, as was shown in an Italian non-asbestos textile industry [23]. Male textile workers showed no increase in risk, but their work activities and exposure may have been different.

It is well known that textile workers have an increased risk of mesothelioma, as was seen in the US [24] and several other countries where asbestos fibers have been a part of the production process. However, no studies have confirmed that exposure to textile fibers alone is carcinogenic. The traditional understanding of mesothelioma incidence in women holds that they are exposed via their husbands; that is, men exposed to asbestos bring home asbestos fibers on their clothes, and their wives are then subjected to secondary asbestos exposure when they handle or wash the clothes. However, we did not find any evidence of such a pattern in the present analysis.

Linkage to the Swedish NOCCA-JEM led to some interesting results. Twelve of the 17 occupations with excess mesothelioma risk were rated for asbestos exposure in the Swedish NOCCAJEM. Five occupations (mechanical engineers and technicians; toolmakers, machine tool setters and operators; chemical process workers; paper pulp workers; and stationary engine and related equipment operators) were rated for chemical exposure in the Swedish NOCCA-JEM, but not for asbestos exposure. It is possible that asbestos exposure occurred in all of these occupations, but that the Swedish NOCCA-JEM is not sensitive enough to rate them as such due to low asbestos prevalence (e.g., a total of 102,447 men had the occupational code of mechanical engineers and technicians in 1980). Moreover, these occupations contain many different activities and tasks that include low asbestos exposure. We excluded all occupations in the Swedish NOCCA-JEM with an exposure prevalence (proportion of exposed individuals in a defined occupation) of less than $5 \%$ for all agents.

Asbestos use was highest in Sweden from 1965 to 1975. Due to a latency period of 30 to 40 years, we should not expect to observe many changes until the last of our three follow-up periods, during which we found an increased risk for sheet metal workers and electrical fitters.

The excess risk for women sewing workers in the first followup period may have been due to exposure during the 1930s and 1940s, for which we do not have information. The same point can also be made for the other occupations that showed decreasing trends.

An important observation is that the following occupations rated for asbestos exposure in the Swedish NOCCA-JEM showed no elevated risk in our data: chemical and cellulose processing work and store and warehouse workers. Furnace men, nonspecific electrical and electronics workers, concrete and construction workers, glass formers and cutters, paper and paperboard workers, and chimney sweeps are all exposed to asbestos in the course of their work. Although they all showed an elevated risk of mesothelioma in our analysis, it was not statistically significant. An increased risk of mesothelioma has been observed in other studies among furnace men and chimney sweeps $[13,25]$.

Male ships' engineers, as well as divers and pipe layers, showed a significant excess risk of mesothelioma of the pleura, but in the Swedish NOCCA-JEM these occupations were not rated for any chemical exposure. Male ships' engineers are more likely to be exposed to asbestos [26].

Among women, canning workers, sorting clerks and postal workers, and packers are not exposed to asbestos, but we found a significant excess risk of mesothelioma of the pleura and peritoneum in these occupations. We have no explanation for these observations. Women working as sewing workers and cleaners also showed a significant excess risk of mesothelioma of the pleura. These occupations do include exposure to textile fibers, but no specific textile fiber has been correlated to mesothelioma in the literature.

A total of $25.5 \%$ of the women with mesothelioma in the present study had mesothelioma of the peritoneum, compared to just $5.9 \%$ of the men. A change in the diagnostic procedures for peritoneal tumors in 1999 may indicate a possibility for misclassification before the year 2000 [27]. Several studies have shown that ovarian and gastrointestinal tumors may be misdiagnosed as mesothelioma of the peritoneum and vice versa [28-30]. The distinction between ovarian cancer and mesothelioma of the peritoneum may also be difficult to detect. A significant excess risk of ovarian cancer has been found among textile workers, graphic workers, packing workers, and workers in the telegraph and telephone industry (a subgroup of postal workers) in Sweden [31], corresponding to employment in both 1960 and 1970. This is in agreement with our observations of excess risk in this study, but no reports have described potential asbestos exposure within these occupations.

Asbestos is known to cause cancer in the wives and children of workers who are heavily exposed to asbestos [32,33]. This association may indicate that even household exposure may play a role in the development of asbestos-related cancers [34]. However, we have no indication as to why the women in the 
high-risk occupations observed in this study would have had higher levels of household exposure than women in other occupations.

Asbestos may have been a contaminant in talc, particularly before the mid-1970s [35]. Talc may be used for hygienic purposes or may be introduced to the women peritoneum through powder-coated gloves used in surgical operations [36]. Heller et al. [37] found asbestos fibers in the ovarian tissue of $69 \%$ of women with household asbestos exposure and in $35 \%$ of those with a history of asbestos exposure. No associations were found between ovarian cancer and occupational exposure to talc in a Norwegian study of pulp and paper employees [38]. In a review of occupational risk factors and ovarian cancer, Shen et al. [39] observed an excess risk of ovarian cancer associated with talc exposure.

Exposure assessment is a weakness in most epidemiological studies. The NOCCA data lack information on smoking habits, but smoking is not expected to affect the risk of mesothelioma [40]. The Swedish NOCCA cohort was analyzed in conjunction with the Swedish NOCCA-JEM, which contains quantitative exposure levels for 25 carcinogenic agents for each year between 1945 and 1994 for 96 different occupations. Never before has any linkage been made using such large and advanced materials.

We have chosen to present the results as they are, in an exploratory manner, and acknowledge that some of the SIRs may have been significant by chance.

We were not able to determine which time scale (age, period, or cohort) influenced the observed trends. This is a weakness in this study and similar studies using SIRs as risk estimates.

Until recently, mesothelioma incidence has increased each year in Sweden, and it is therefore important to investigate the context of this increase, as we do not currently have a full understanding of the situation. There is no reason to believe that asbestos is the only causative agent of mesothelioma, or that the disease will disappear over time due to reduced asbestos exposure. Therefore, it is important to identify other potential airborne risk factors that may be liabilities to the working population. The follow-up time after the asbestos ban in Sweden is too short (9-17 years in the latest follow-up period) to illustrate that effect.

\section{ACKNOWLEDGEMENTS}

We would like to thank Mrs. Pouran Almstedt, Dr.Timo Kauppinen, Professor Eero Pukkula, and the NOCCA Study Group for their contributions and assistance with this study. The present study was supported by a grant from AFA Insurance.

\section{CONFLICT OF INTEREST}

The authors have no conflicts of interest to declare for this study.

\section{ORCID}

Nils Plato http://orcid.org/0000-0002-4226-1730

Jan Ivar Martinsen http://orcid.org/0000-0002-5684-2878

Pär Sparén http://orcid.org/0000-0002-5184-8971

ElisabeteWeiderpass http://orcid.org/0000-0003-2237-0128

\section{REFERENCES}

1. Wagner JC, Sleggs CA, Marchand P. Diffuse pleural mesothelioma and asbestos exposure in the North Western Cape Province. Br J Ind Med 1960;17:260-271.

2. Van Gelder T, Damhuis RA, Hoogsteden HC. Prognostic factors and survival in malignant pleural mesothelioma. Eur Respir J 1994;7:10351038.

3. Berry G, Reid A, Aboagye-Sarfo P, de Klerk NH, Olsen NJ, Merler E, et al. Malignant mesotheliomas in former miners and millers of crocidolite at Wittenoom (Western Australia) after more than 50 years follow-up. Br J Cancer 2012;106:1016-1020.

4. Bianchi C1, Bianchi T. Malignant mesothelioma: global incidence and relationship with asbestos. Ind Health 2007;45:379-387.

5. National Board of Health and Welfare. The Swedish cancer environment regristry 2011. Stockholm: National Board of Health and Welfare; 2011 (Swedish).

6. Albin M, Pooley FD, Strömberg U, Attewell R, Mitha R, Johansson L, et al. Retention patterns of asbestos fibres in lung tissue among asbestos cement workers. Occup Environ Med 1994;51:205-211.

7. Swedish Work Environment Authority. Asbestos. Solna: Swedish Work Environment Authority; 1982, p. 23 (Swedish).

8. National Board of Health and Welfare (Socialstyrelsen). The Swedish cancer regristry 2012. Stockholm: National Board of Health and Welfare; 2012 (Swedish).

9. Bengtsson B. ISA - The Swedish information system for occupational accidents and work-related diseases: scope, content and quality. Stockholm: Swedish Work Environment Authotity Board; 2011 (Swedish).

10. Roelofs CR, Kernan GJ, Davis LK, Clapp RW, Hunt PR. Mesothelioma and employment in massachusetts: analysis of cancer registry data 1988-2003. Am J Ind Med 2013;56:985-992.

11. Proietti L, Spicuzza L, Di Maria A, Polosa R, Sebastian Torres E, Asero $\mathrm{V}$, et al. Non-occupational malignant pleural mesothelioma due to asbestos and non-asbestos fibres. Monaldi Arch Chest Dis 2006; 65:210-216.

12. Rushton L, Bagga S, Bevan R, Brown TP, Cherrie JW, Holmes P, et al. Occupation and cancer in Britain. Br J Cancer 2010;102:1428-1437.

13. Nurminen M, Karjalainen A. Epidemiologic estimate of the proportion of fatalities related to occupational factors in Finland. Scand J Work Environ Health 2001;27:161-213.

14. Pukkala E, Martinsen JI, Lynge E, Gunnarsdottir HK, Sparén P, Tryggvadottir L, et al. Occupation and cancer - follow-up of 15 million people in five Nordic countries. Acta Oncol 2009;48:646-790. 
15. Goswami E, Craven V, Dahlstrom DL, Alexander D, Mowat F. Domestic asbestos exposure: a review of epidemiologic and exposure data. Int J Environ Res Public Health 2013;10:5629-5670.

16. Department of Labour. Nordic classification of occupations. Oslo: Department of Labour; 1958, p. 1-285 (Norwegian).

17. International Labour Office. International standard classification of occupations. Geneva: International Labour Office; 1958.

18. World Health Organization. ICD-7: manual of the international statistical classification of diseases, injuries, and cause of death. Geneva: World Health Organization; 1957.

19. Kauppinen T, Heikkilä P, Plato N, Woldbaek T, Lenvik K, Hansen J, et al. Construction of job-exposure matrices for the Nordic Occupational Cancer Study (NOCCA). Acta Oncol 2009;48:791-800.

20. Kauppinen T, Toikkanen J, Pukkala E. From cross-tabulations to multipurpose exposure information systems: a new job-exposure matrix. Am J Ind Med 1998;33:409-417.

21. Boffetta P. Epidemiology of peritoneal mesothelioma: a review. Ann Oncol 2007; 18:985-990.

22. Mensi C, Giacomini S, Sieno C, Consonni D, Riboldi L. Pericardial mesothelioma and asbestos exposure. Int J Hyg Environ Health 2011; 214:276-279.

23. Chiappino G, Pellissetti D, Moretto O, Picchi O. Asbestos risk in the textile industry: braking systems on machinery used until the 1990's. Med Lav 2005;96:250-257 (Italian).

24. Loomis D, Dement JM, Elliott L, Richardson D, Kuempel ED, Stayner L. Increased lung cancer mortality among chrysotile asbestos textile workers is more strongly associated with exposure to long thin fibres. Occup Environ Med 2012;69:564-568.

25. Hogstedt C, Jansson C, Hugosson M, Tinnerberg H, Gustavsson P. Cancer incidence in a cohort of Swedish chimney sweeps, 1958-2006. Am J Public Health 2013;103: 1708-1714.

26. Filon FL, Negro C, De Michieli P, Bovenzi M. Asbestos related cancers in seamen. G Ital Med Lav Ergon 2013;35:206-210 (Italian).

27. Burdorf A, Järvholm B, Siesling S. Asbestos exposure and differences in occurrence of peritoneal mesothelioma between men and women across countries. Occup Environ Med 2007;64:839-842.

28. Wright WE, Sherwin RP, Dickson EA, Bernstein L, Fromm JB, Hen- derson BE. Malignant mesothelioma: incidence, asbestos exposure, and reclassification of histopathology. Br J Ind Med 1984;41:39-45.

29. Nielsen AM, Olsen JH, Madsen PM, Francis D, Almind M. Peritoneal mesotheliomas in Danish women: review of histopathologic slides and history of abdominal surgery. Acta Obstet Gynecol Scand 1994;73:581-585.

30. Daya D, McCaughey WT. Well-differentiated papillary mesothelioma of the peritoneum. A clinicopathologic study of 22 cases. Cancer 1990;65:292-296.

31. Shields T, Gridley G, Moradi T, Adami J, Plato N, Dosemeci M. Occupational exposures and the risk of ovarian cancer in Sweden. Am J Ind Med 2002;42:200-213.

32. Kane MJ, Chahinian AP, Holland JF. Malignant mesothelioma in young adults. Cancer 1990;65:1449-1455.

33. Schneider J, Straif K, Woitowitz HJ. Pleural mesothelioma and household asbestos exposure. Rev Environ Health 1996;11:65-70.

34. Magnani C, Dalmasso P, Biggeri A, Ivaldi C, Mirabelli D, Terracini B. Increased risk of malignant mesothelioma of the pleura after residential or domestic exposure to asbestos: a case-control study in Casale Monferrato, Italy. Environ Health Perspect 2001;109:915-919.

35. Cramer DW, Welch WR, Scully RE, Wojciechowski CA. Ovarian cancer and talc: a case-control study. Cancer 1982;50:372-376.

36. Langseth H, Johansen BV, Nesland JM, Kjaerheim K. Asbestos fibers in ovarian tissue from Norwegian pulp and paper workers. Int $\mathrm{J}$ Gynecol Cancer 2007; 17:44-49.

37. Heller DS, Gordon RE, Westhoff C, Gerber S. Asbestos exposure and ovarian fiber burden. Am J Ind Med 1996;29:435-439.

38. Langseth H, Kjaerheim K. Ovarian cancer and occupational exposure among pulp and paper employees in Norway. Scand J Work Environ Health 2004;30:356-361.

39. Shen N, Weiderpass E, Antilla A, Goldberg MS, Vasama-Neuvonen KM, Boffetta P, et al. Epidemiology of occupational and environmental risk factors related to ovarian cancer. Scand J Work Environ Health 1998;24:175-182.

40. Muscat JE, Wynder EL. Cigarette smoking, asbestos exposure, and malignant mesothelioma. Cancer Res 1991;51:2263-2267. 
Appendix 1. Exposure codes, exposures, and units used in the Swedish job-exposure matrix

\begin{tabular}{lll}
\hline Exposure code & \multicolumn{1}{c}{ Exposure } & Unit \\
\hline ALHC & Aliphatic and alicyclic hydrocarbon solvents & $\mathrm{ppm}$ \\
ANIM & Animal-borne dust & $\mathrm{mg} / \mathrm{m}^{3}$ \\
ARHC & Aromatic hydrocarbon solvents & $\mathrm{ppm}$ \\
ASB & Asbestos & $\mathrm{f} / \mathrm{cm}^{3}$ \\
BAP & Benzo(a)pyrene & $\mathrm{\mu g} / \mathrm{m}^{3}$ \\
BITU & Bitumen fumes & $\mathrm{mg} / \mathrm{m}^{3}$ \\
CHC & Chlorinated hydrocarbon solvents & $\mathrm{ppm}$ \\
CR & Chromium & $\mathrm{\mu g} / \mathrm{m}^{3}$ \\
DEEX & Diesel engine exhaust & $\mathrm{mg} / \mathrm{m}^{3}$ \\
FE & Iron & $\mathrm{mg} / \mathrm{m}^{3}$ \\
FORM & Formaldehyde & $\mathrm{ppm}$ \\
GASO & Gasoline & $\mathrm{ppm}$ \\
NI & Nickel & $\mathrm{\mu g} / \mathrm{m}^{3}$ \\
OSOL & Other organic solvents & $\mathrm{ppm}$ \\
PB & Lead & $\mathrm{\mu mol} / \mathrm{L}$ \\
QUAR & Quartz dust & $\mathrm{mg} / \mathrm{m}^{3}$ \\
SO & Sulfur dioxide & $\mathrm{ppm}$ \\
WOOD & Wood dust & $\mathrm{mg} / \mathrm{m}^{3}$ \\
WELD & Welding fumes & $\mathrm{mg} / \mathrm{m}^{3}$ \\
BENZ & Benzene & $\mathrm{ppm}$ \\
MCH & Methylene chloride & $\mathrm{ppm}$ \\
TOLU & Toluene & $\mathrm{ppm}$ \\
PER & Perchloroethylene & $\mathrm{ppm}$ \\
TCE & 1, 1, 1-trichloroethane & $\mathrm{ppm}$ \\
TRI & Trichloroethylene & $\mathrm{ppm}$ \\
UV & Ultraviolet radiation & $\mathrm{J} / \mathrm{m}^{2}$ \\
IRAD & lonizing radiation & $\mathrm{mSv}$ \\
PPWL & Perceived physical work load & $\mathrm{score}$ \\
NIGH & Night work & $\mathrm{none}$ \\
NOEXP & No exposure to any known carcinogens & $\mathrm{none}$ \\
\hline & & \\
\hline
\end{tabular}




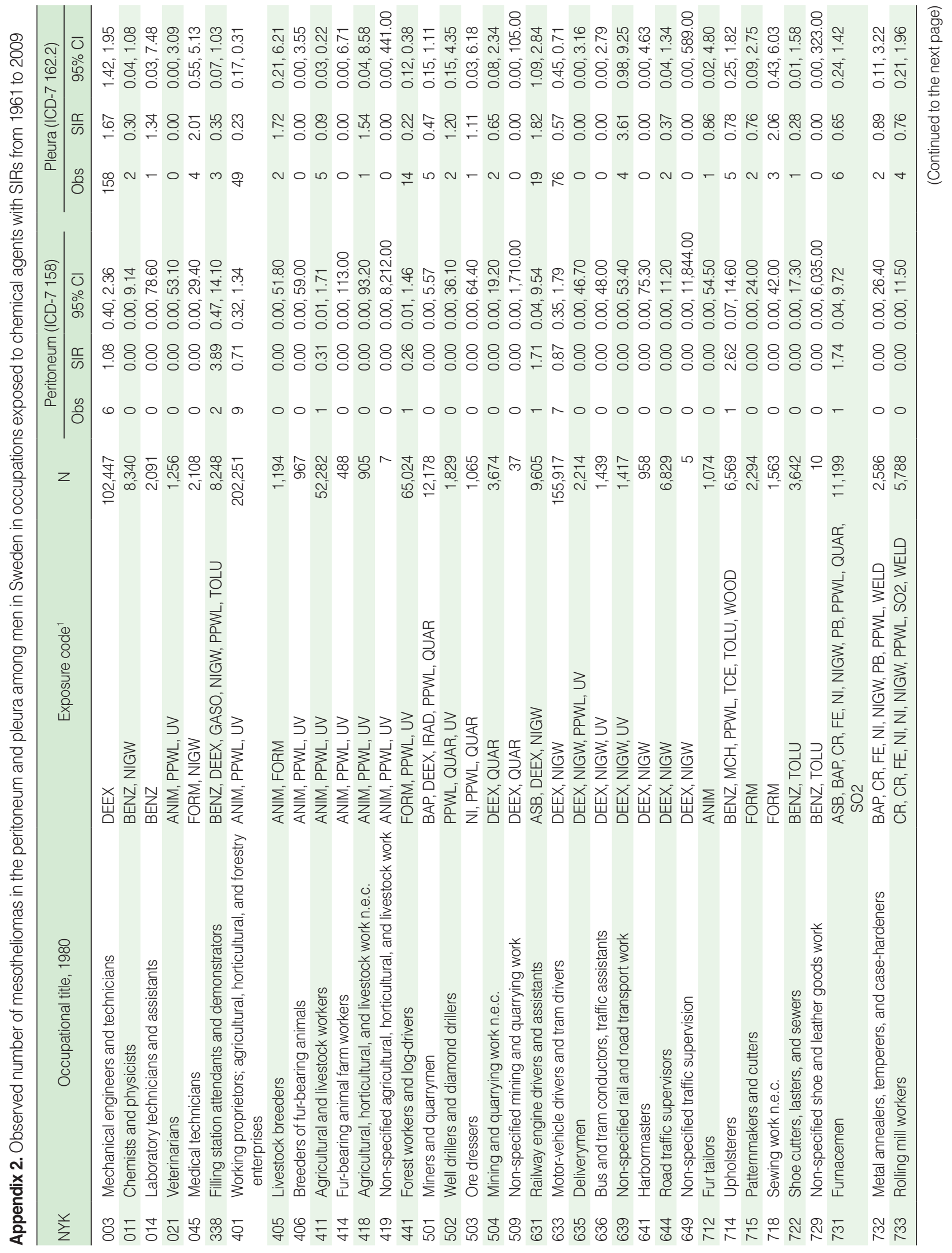




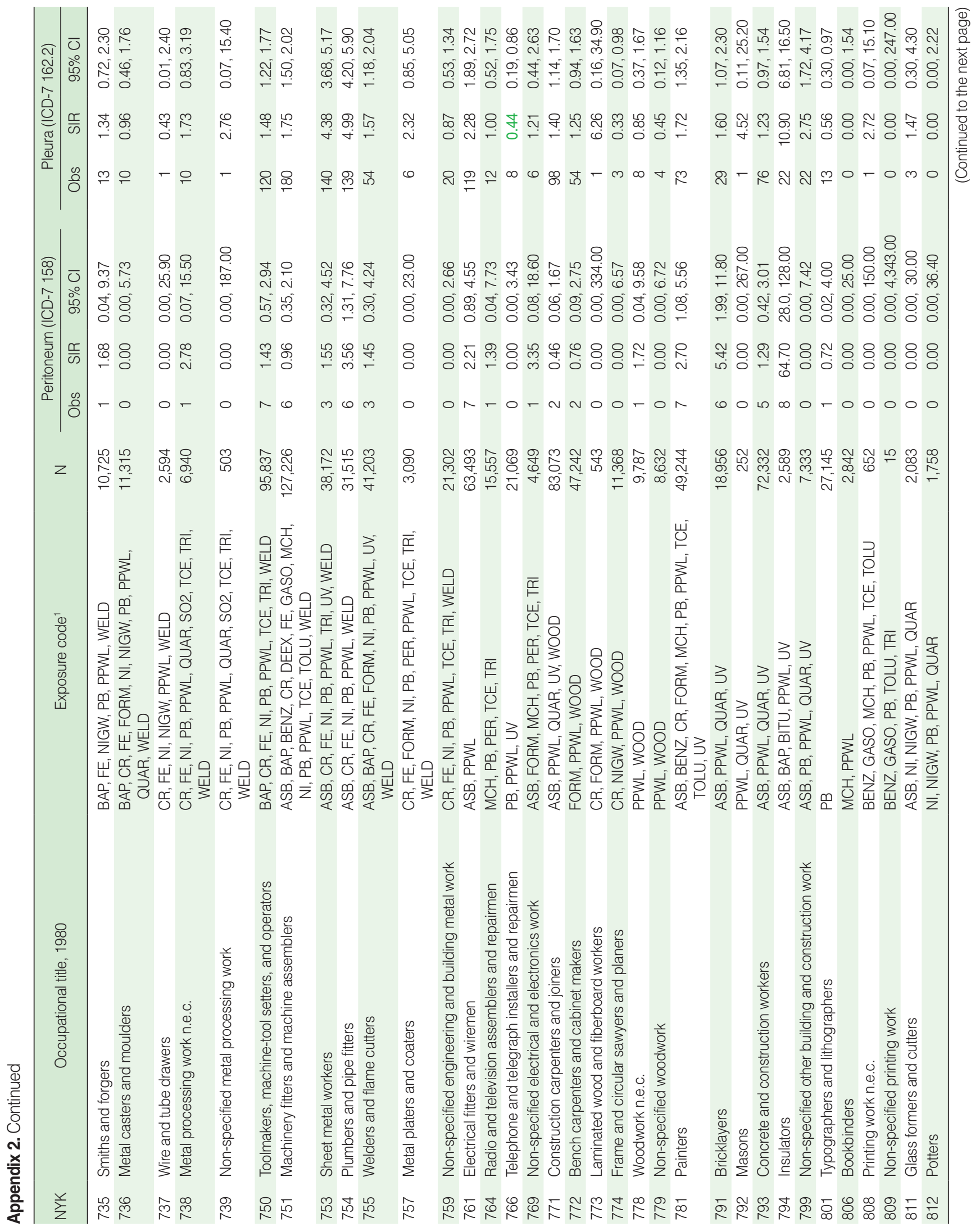




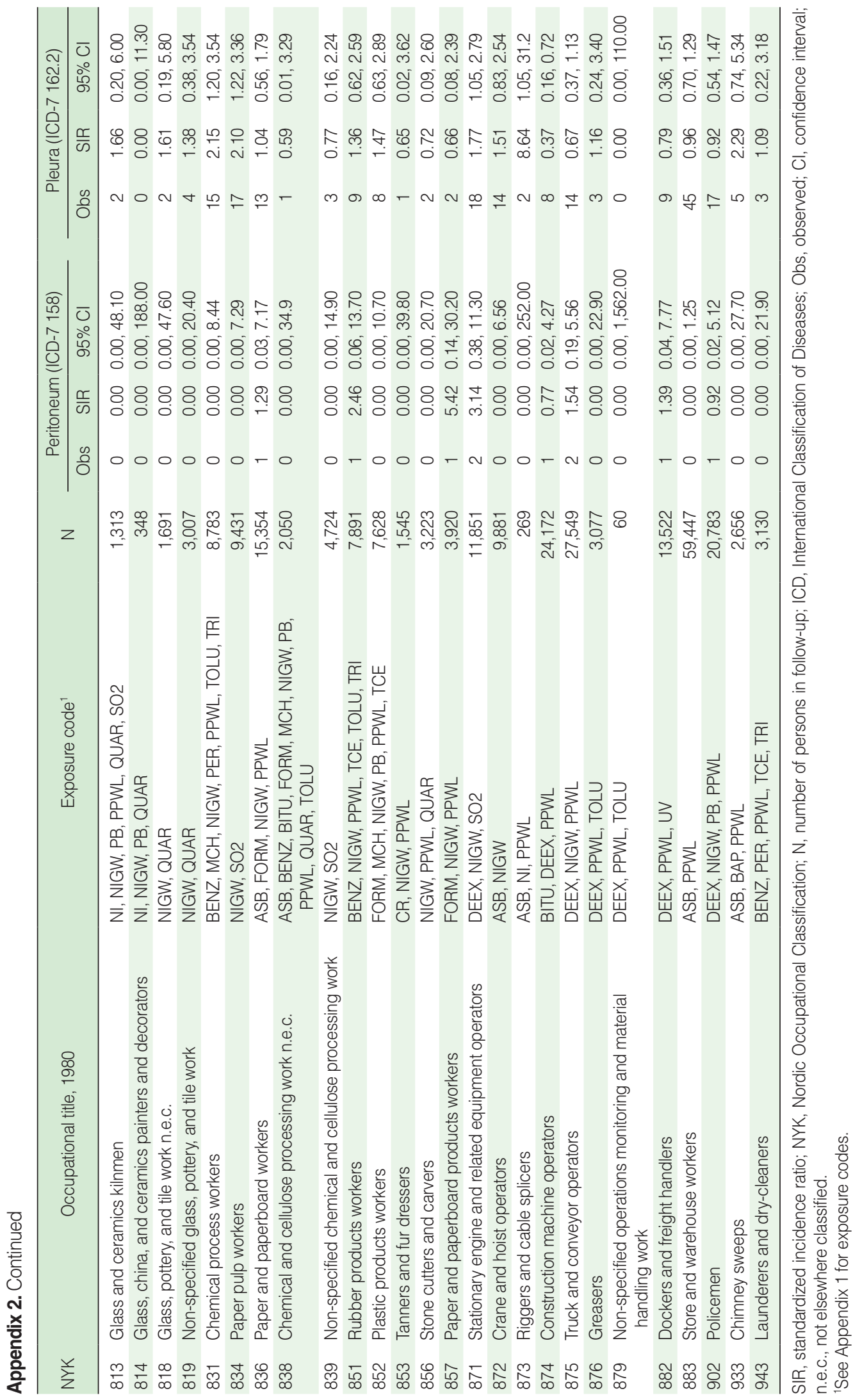




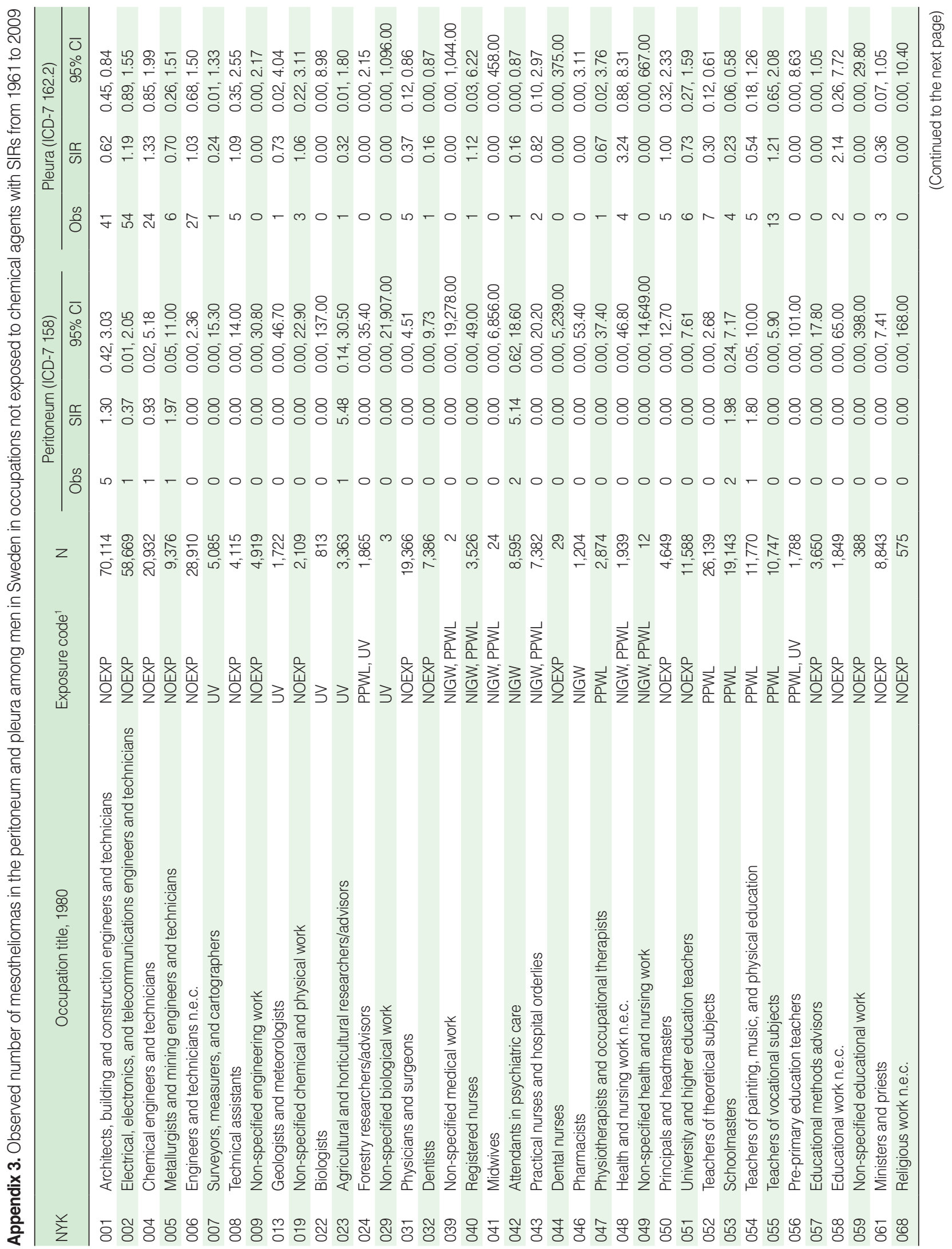




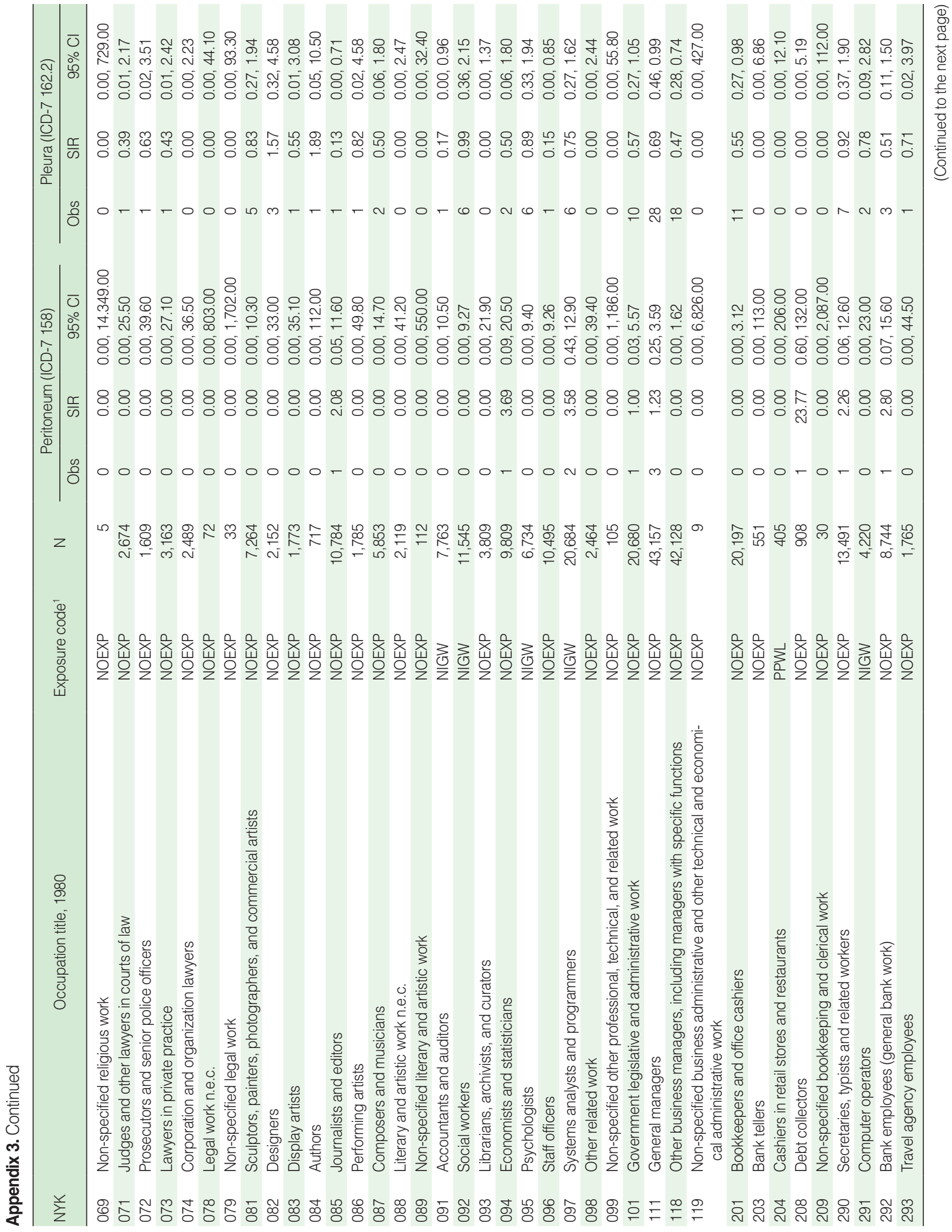




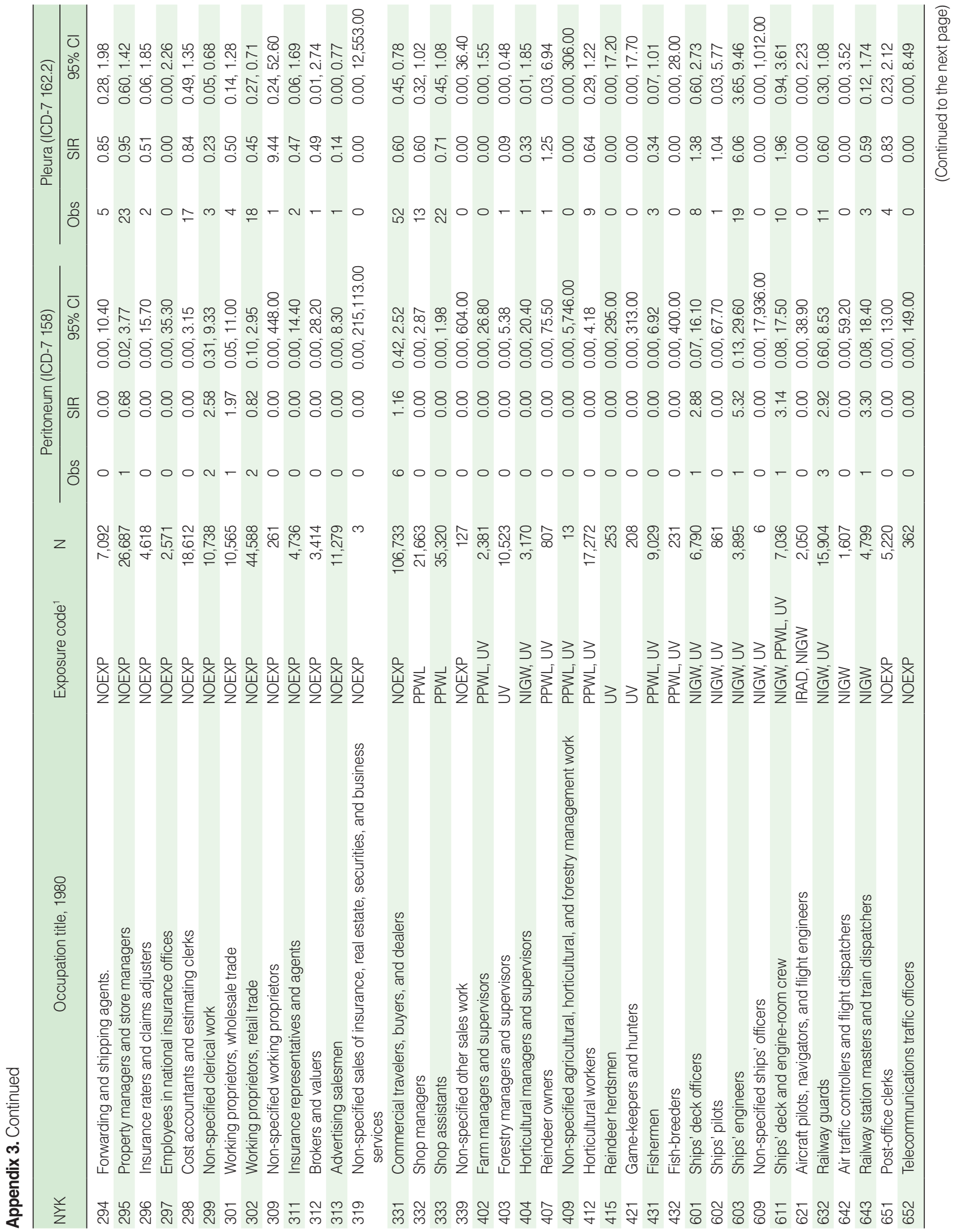




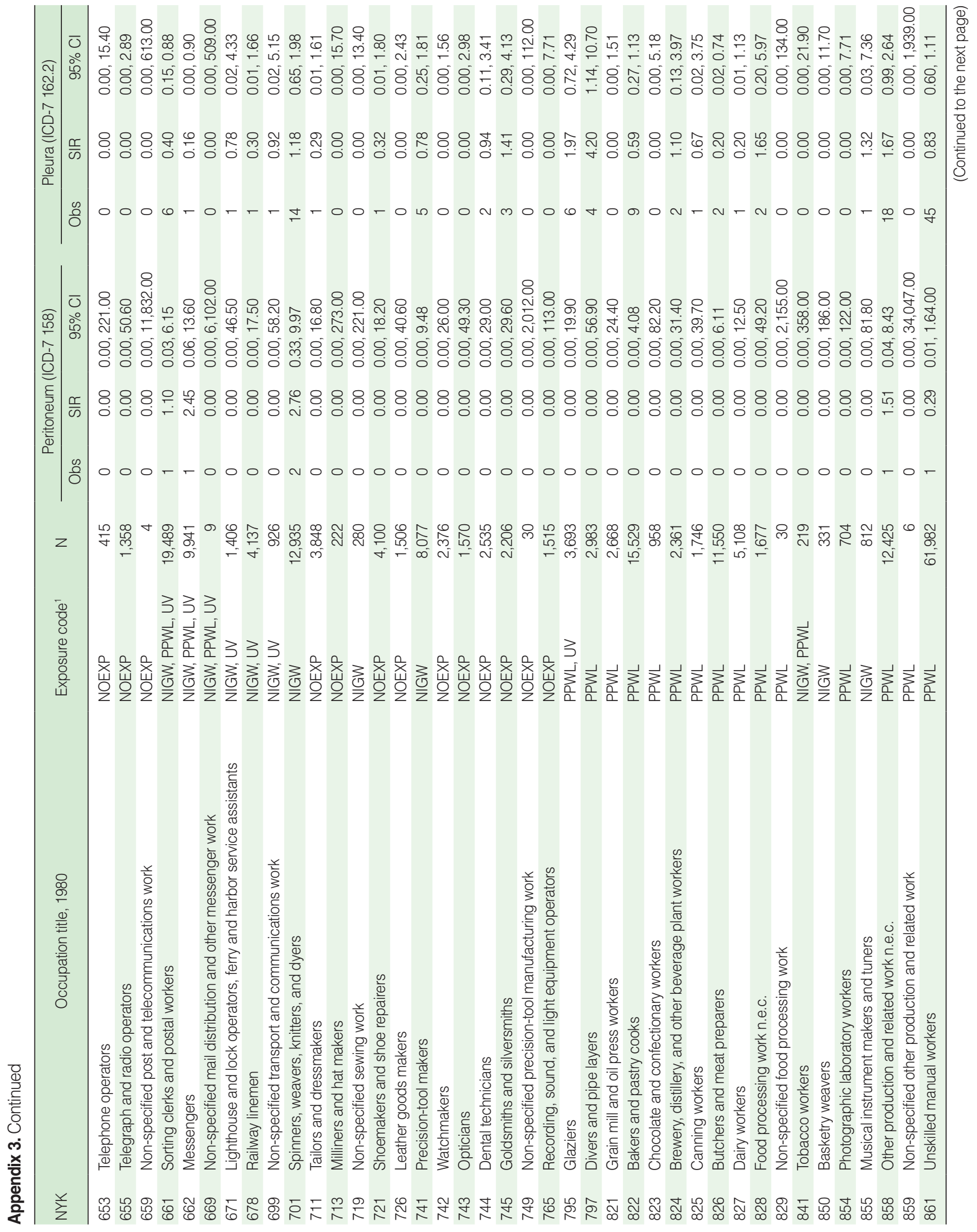




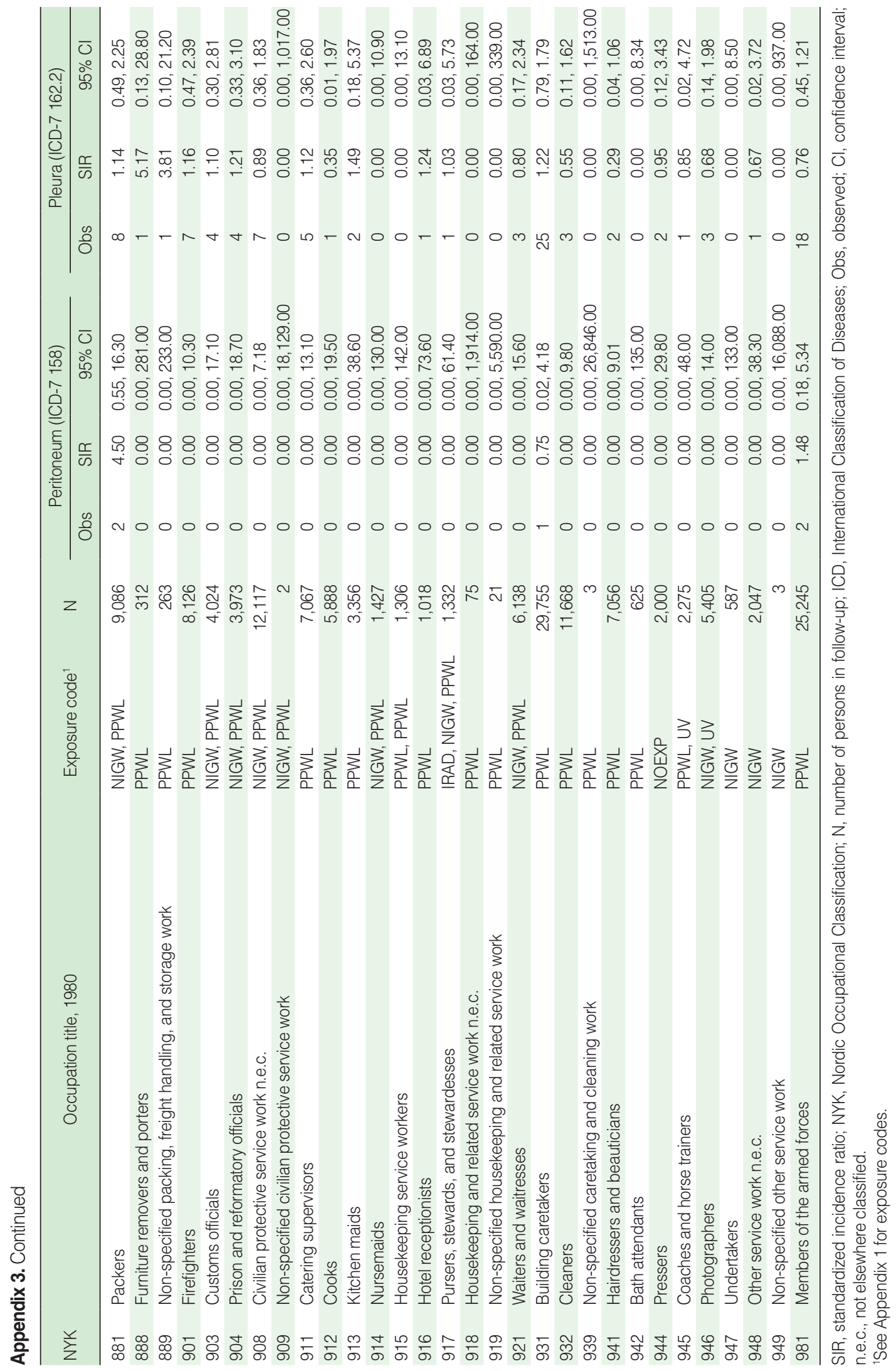




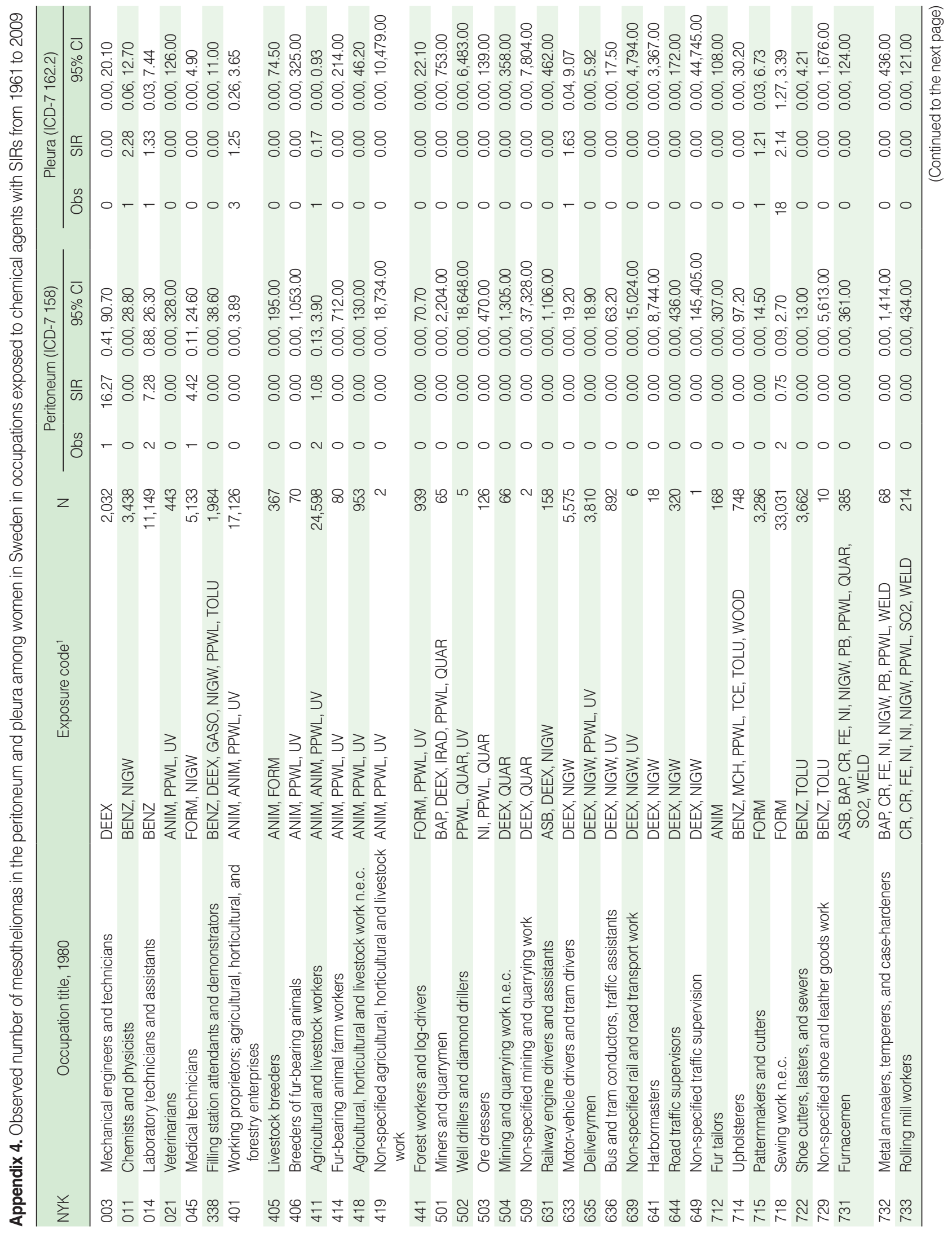




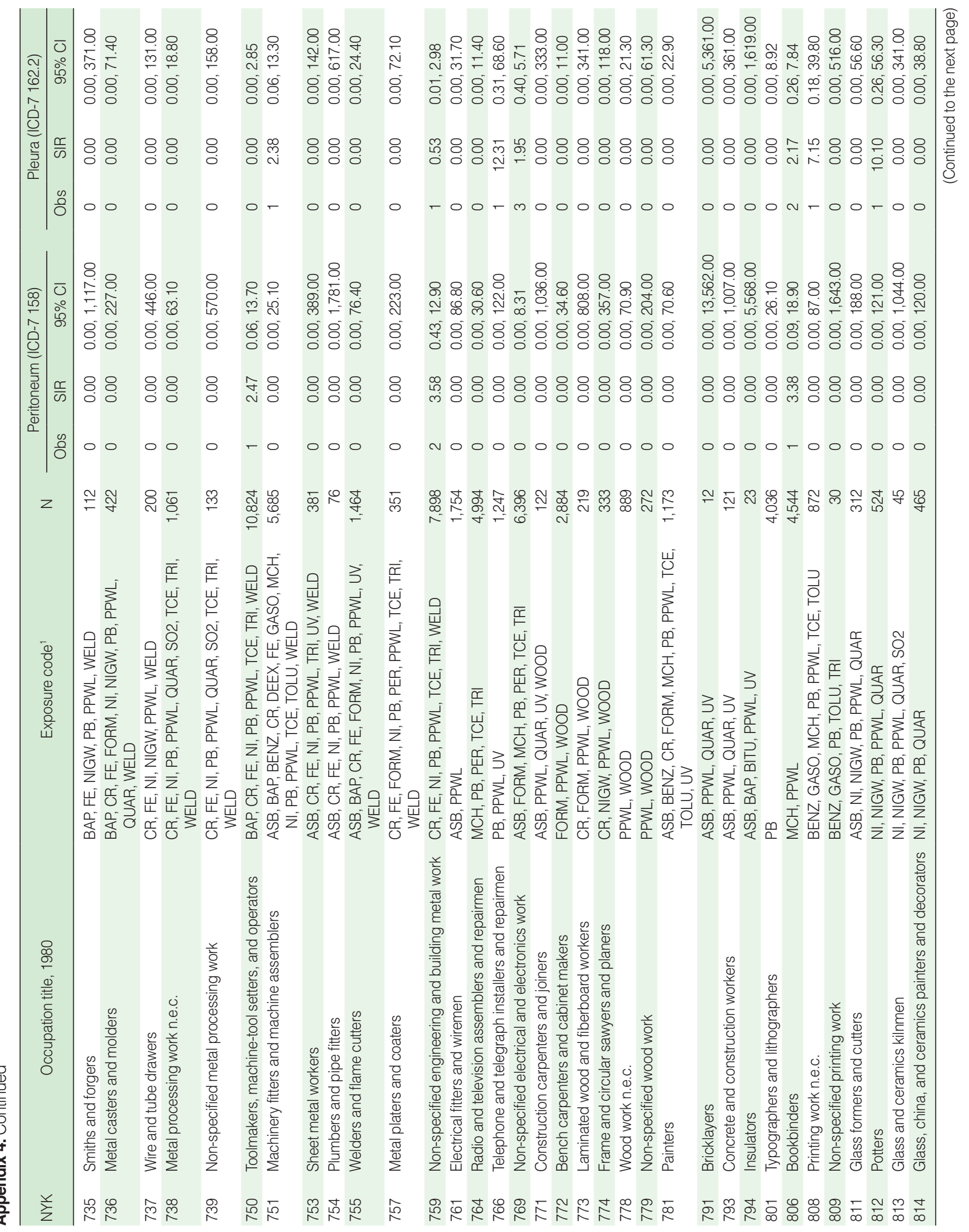




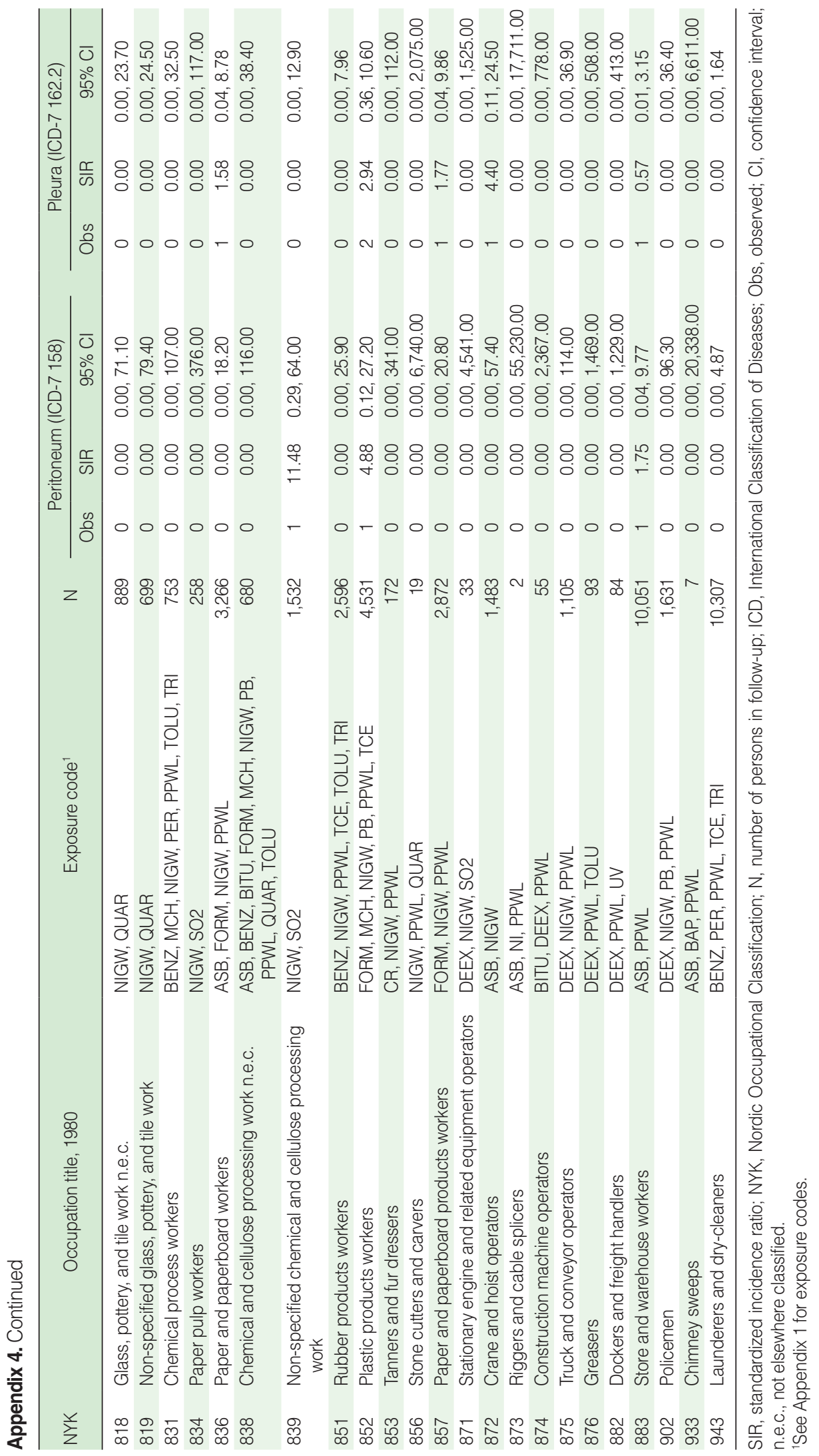




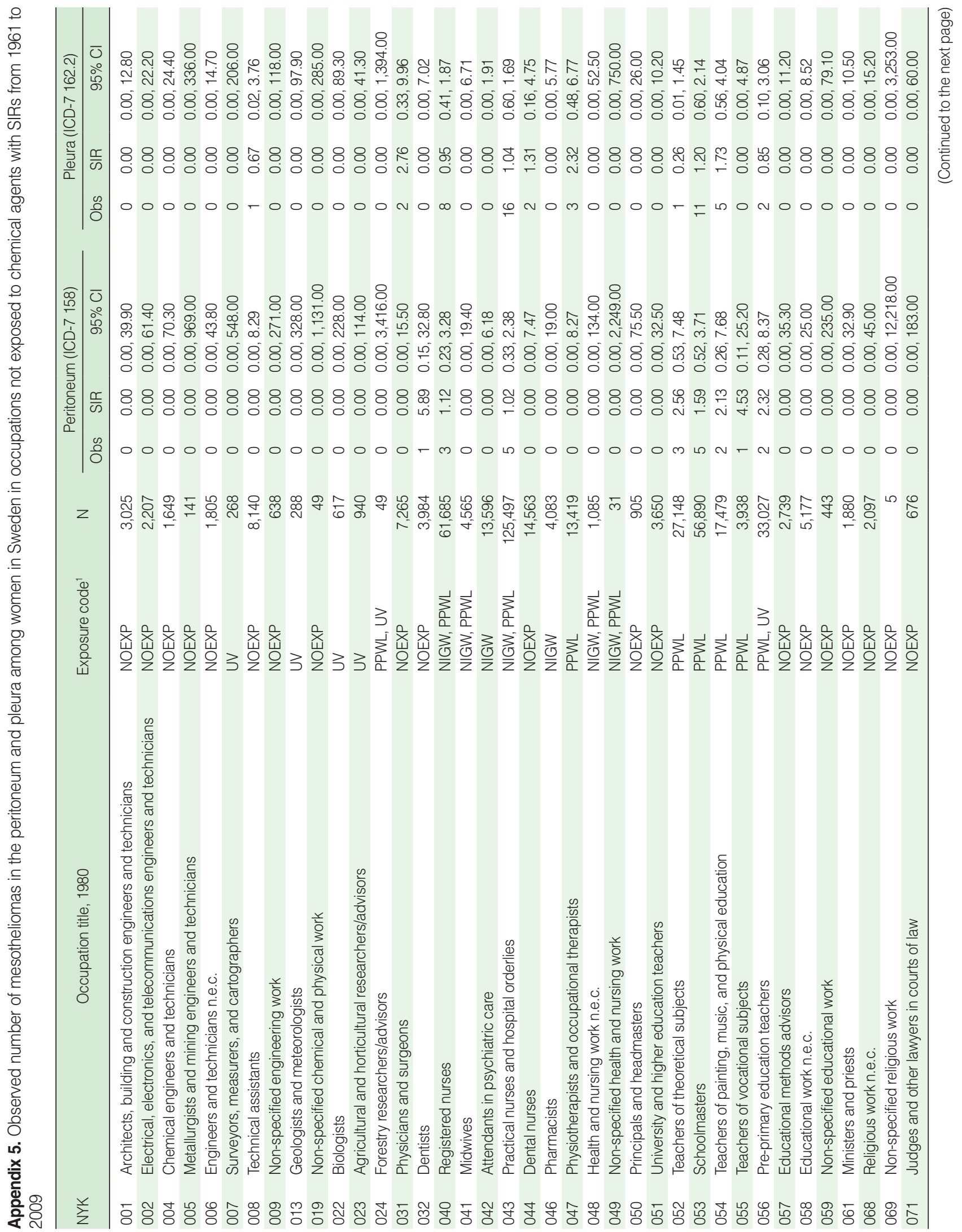




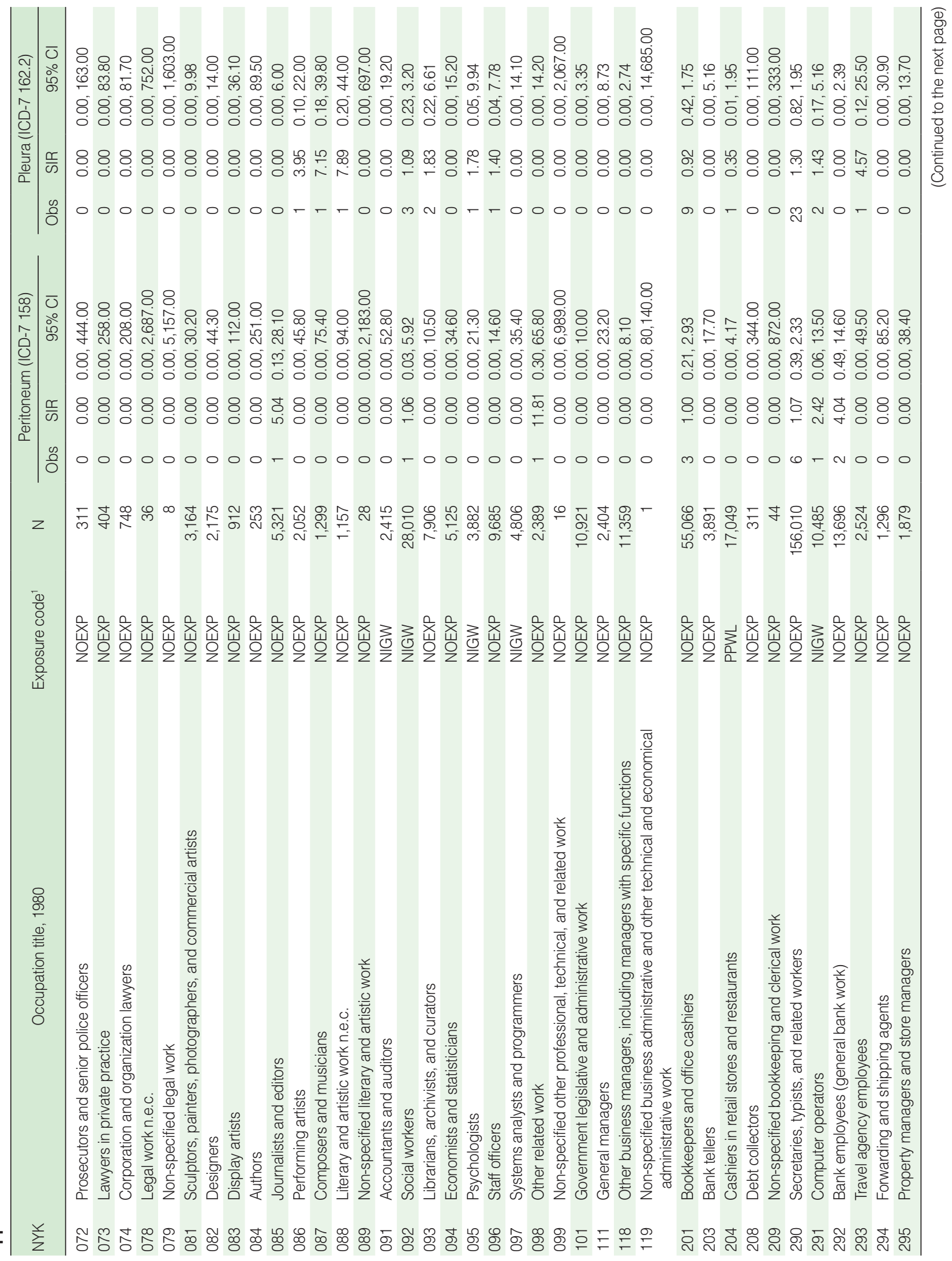




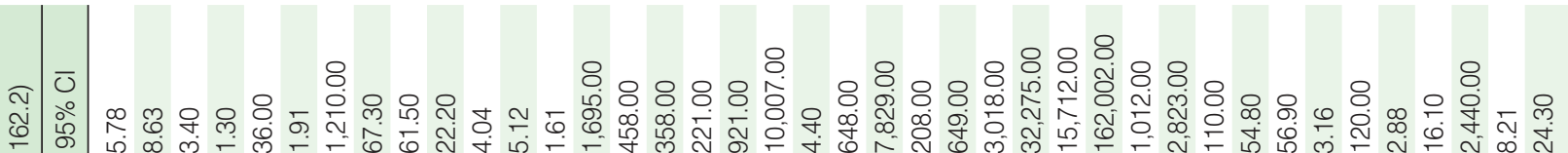
ภำ

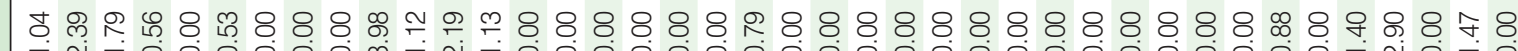

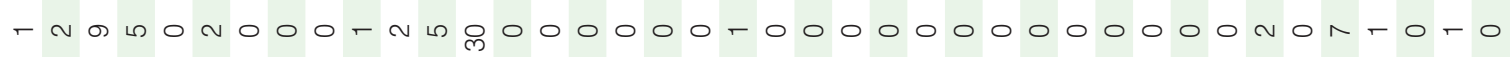

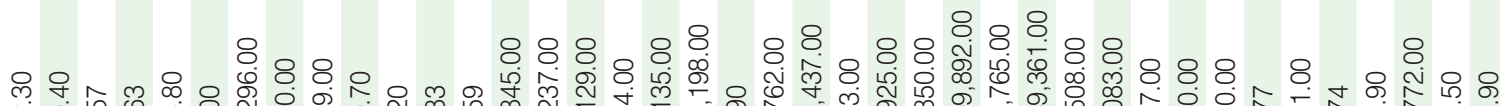

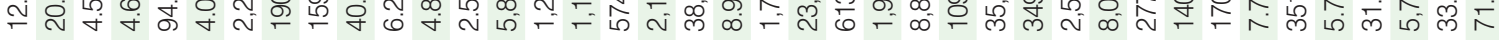

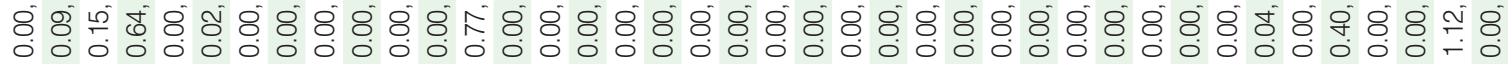

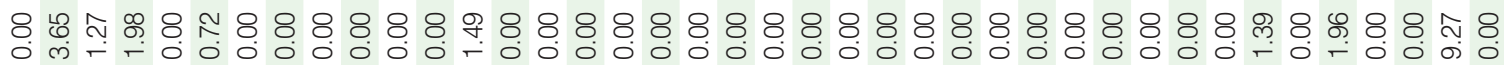
$0-n$ n

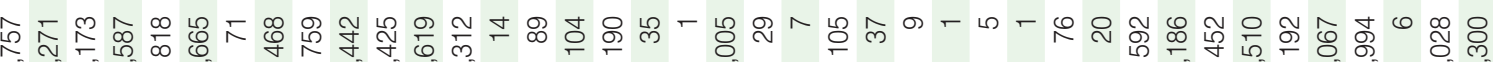

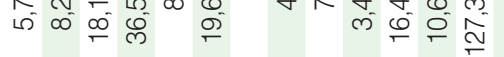

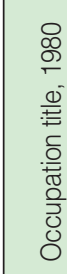
(1)
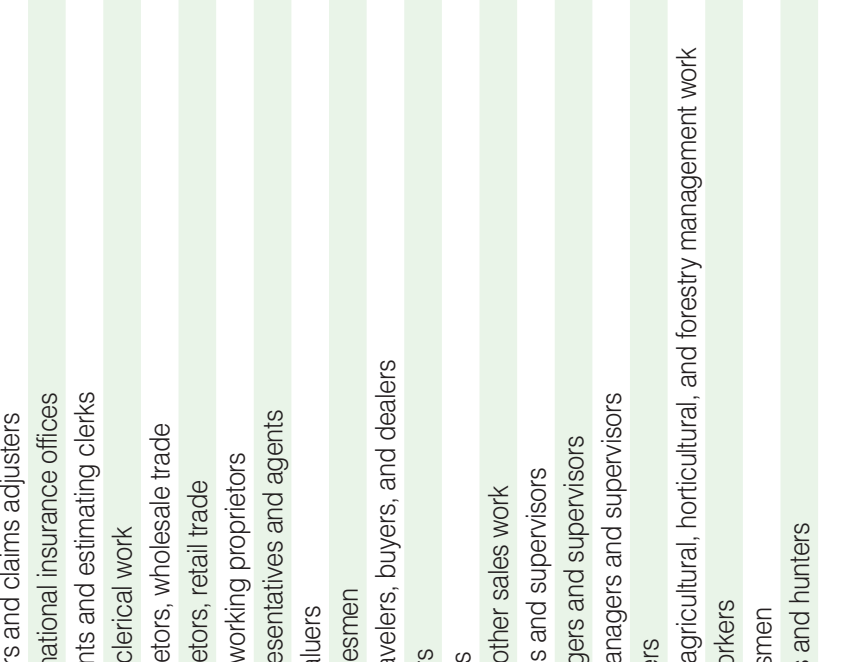

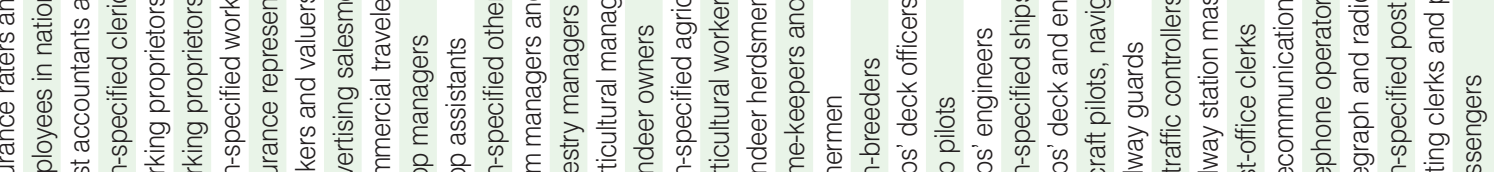

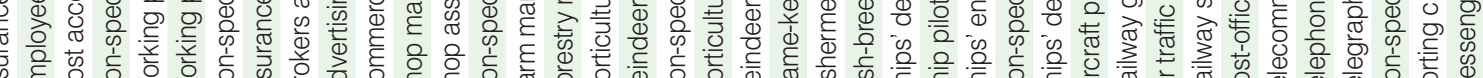

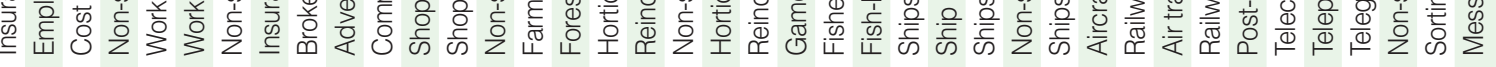

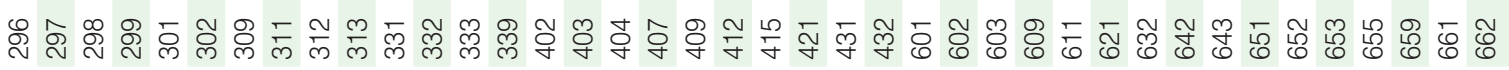




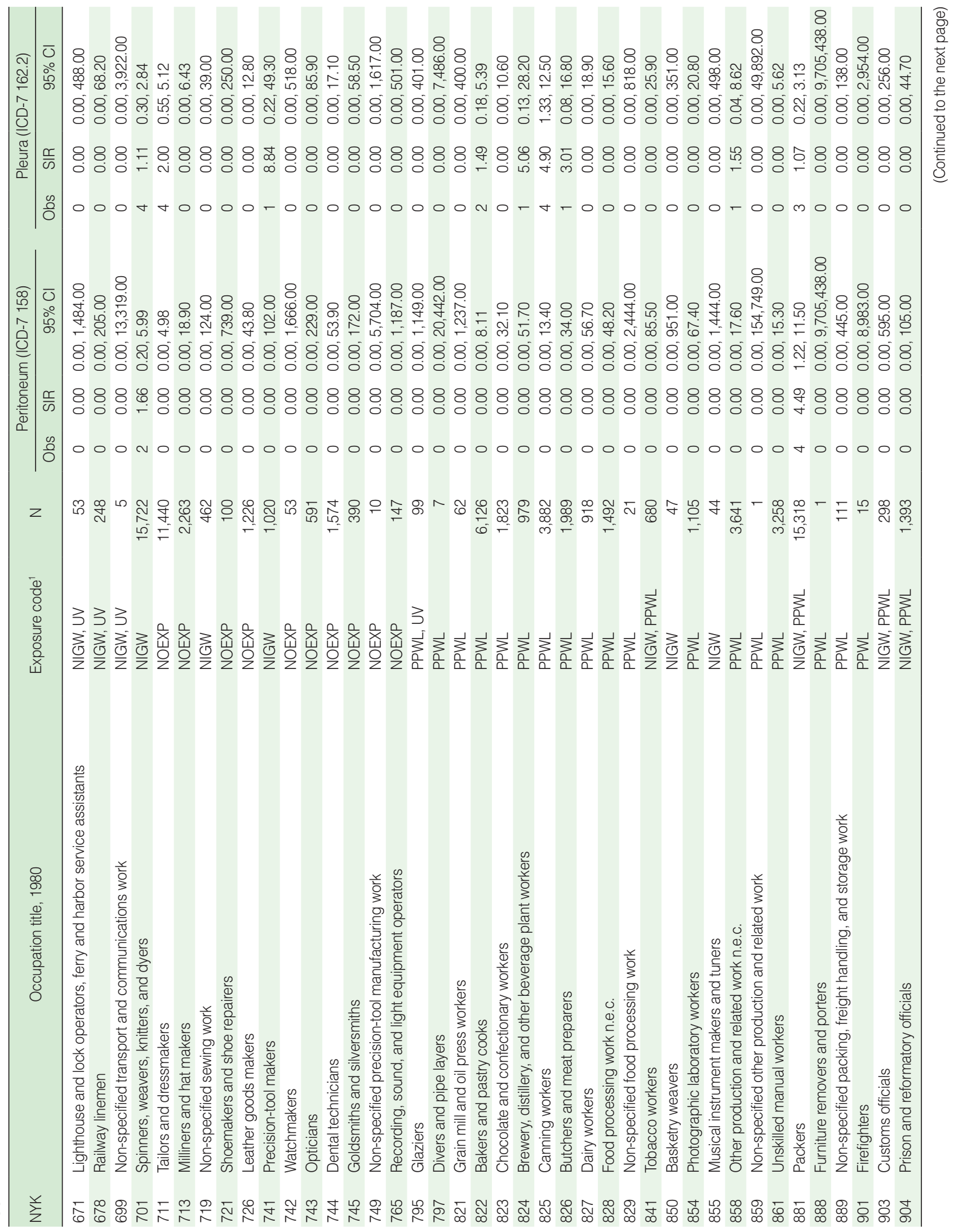




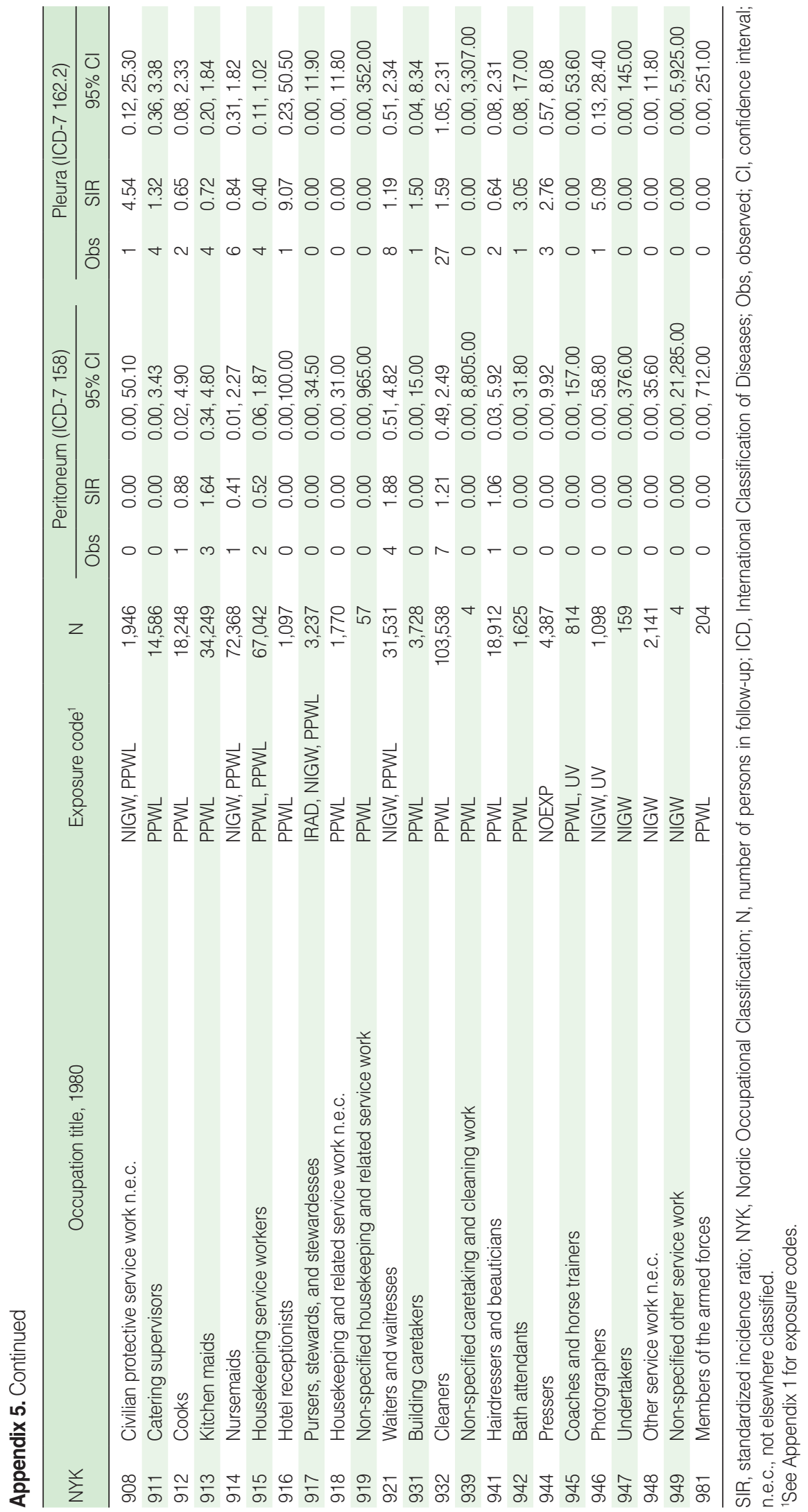

